\title{
Discovery of genetic biomarkers contributing to variation in drug response of cytidine analogues using human lymphoblastoid cell lines
}

\author{
Liang Li', Brooke L Fridley ${ }^{2,3}$, Krishna Kalari ${ }^{2}$, Nifang Niu', Gregory Jenkins², Anthony Batzler², Ryan P Abo',
} Daniel Schaid ${ }^{2}$ and Liewei Wang ${ }^{2^{*}}$

\begin{abstract}
Background: Two cytidine analogues, gemcitabine and cytosine arabinoside (AraC), are widely used in the treatment of a variety of cancers with a large individual variation in response. To identify potential genetic biomarkers associated with response to these two drugs, we used a human lymphoblastoid cell line (LCL) model system with extensive genomic data, including 1.3 million SNPs and 54,000 basal expression probesets to perform genome-wide association studies (GWAS) with gemcitabine and AraC IC50 values.

Results: We identified 11 and 27 SNP loci significantly associated with gemcitabine and AraC IC50 values, respectively. Eleven candidate genes were functionally validated using siRNA knockdown approach in multiple cancer cell lines. We also characterized the potential mechanisms of genes by determining their influence on the activity of 10 cancer-related signaling pathways using reporter gene assays. Most SNPs regulated gene expression in a trans manner, except 7 SNPs in the PIGB gene that were significantly associated with both the expression of PIGB and gemcitabine cytotoxicity.

Conclusion: These results suggest that genetic variation might contribute to drug response via either cis- or trans- regulation of gene expression. GWAS analysis followed by functional pharmacogenomics studies might help identify novel biomarkers contributing to variation in response to these two drugs and enhance our understanding of underlying mechanisms of drug action.
\end{abstract}

Keywords: Cytidine analogues, Gemcitabine, Cytosine arabinoside, Lymphoblastoid cell lines, Expression array, Genome-wide SNPs, Genome-wide association study, Functional genomics, Translational research

\section{Background}

Both gemcitabine and $\mathrm{AraC}$ are widely used in the treatment of a variety of cancers and both display wide individual variation in drug response [1-6]. Pharmacogenomic studies have the potential to provide insight into mechanisms underlying individual variation in response to these two drugs [7-11]. Many previous pharmacogenetic studies focused on the bioactivation and metabolism pathways for cytidine analogues $[12,13]$. For example, SNPs in genes encoding ribonucleotide reductase (RRM1) and cytidine

\footnotetext{
* Correspondence: wang.liewei@mayo.edu

${ }^{2}$ Division of Biomedical Statistics and Informatics, Department of Health

Sciences Research, Mayo Clinic, Rochester, Minnesota, USA

Full list of author information is available at the end of the article
}

deaminase $(C D A)$ were found to be associated with gemcitabine chemosensitivity in the NCI-60 cell lines or with active gemcitabine metabolite plasma levels [14-16]. Those findings provided the initial evidence that genetic variation might contribute to variation in cytidine analogue response. We previously used the "Human Variation Panel", a genomic data-rich lymphoblastoid cell line model system, to identify markers that might contribute to variation in response to these two cytidine analogues $[17,18]$. These cell lines have proven to be a powerful tool for both the identification of pharmacogenomic hypotheses and for the pursuit of hypotheses from the clinical GWAS [19-21]. However, the earlier studies were performed with less dense SNP coverage, in the present study, we expanded our previous $550 \mathrm{~K} \mathrm{SNP}$ data to include a total of 1.3

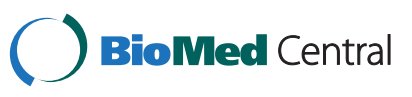

(c) 2014 Li et al.; licensee BioMed Central Ltd. This is an open access article distributed under the terms of the Creative Commons Attribution License (http://creativecommons.org/licenses/by/2.0), which permits unrestricted use, distribution, and reproduction in any medium, provided the original work is properly cited. 
million SNPs obtained with both Illumina and Affymetrix SNP genotyping platforms in an attempt to identify additional genes or SNPs that might be associated with drug response. To follow-up the candidates, we performed functional studies using tumor cell lines in an attempt to determine possible underlying mechanisms that might help us to better understand mechanisms of action for these two drugs. The results of the comprehensive series of experiments described subsequently resulted in the identification of several novel SNPs and genes associated with gemcitabine and $\mathrm{AraC}$ drug response in these cell lines. These results could be tested in future clinical studies to determine whether they might help predict response to gemcitabine and AraC.

\section{Methods \\ Cell lines}

One hundred and seventy four human lymphoblastoid cell lines from 60 Caucasian-American (CA), 54 AfricanAmerican (AA) and 60 Han Chinese-American (HCA) (sample sets HD100CAU, HD100AA, and HD100CHI) subjects were purchased from the Coriell Cell Repository (Camden, NJ). All of these cell lines had been obtained and anonymized by the National Institute of General Medical Sciences prior to deposit, and all subjects had provided written consent for the use of their DNA and cells for experimental purposes. Human SU86 pancreatic cancer cell lines were a gift from Dr. Daniel D. Billadeau (Department of Immunology and Division of Oncology Research, Mayo Clinic College of Medicine). Human breast cancer MDA-MB-231 and leukemia BDCM and THP-1 cell lines were purchased from the American Type Culture Collection (ATCC) (Manassas, VA) and were cultured in DMEM with 1\% L-glutamine (Mediatech) supplemented with 10\% FBS (Mediatech). Other cell lines were maintained in RPMI medium 1640 with 1\% L-glutamine (Mediatech) supplemented with 10\% FBS (Mediatech).

\section{Drugs and cell proliferation assays}

Gemcitabine was provided by Eli Lilly (Indianapolis, IN). AraC was purchased from Sigma-Aldrich (St. Louis, $\mathrm{MO})$. Cytotoxicity assays with the lymphoblastoid and tumor cell lines were performed with the CellTiter $96^{\circledR}$ $\mathrm{AQ}_{\text {ueous }}$ Non-Radioactive Cell Proliferation Assay (Promega Corporation, Madison, WI) as previously described [17]. $\mathrm{IC}_{50}$ values were calculated using a three or four parameter logistic model with the R package "drc" (http://cran. r-project.org/web/packages/drc/drc.pdf), as described previously [18].

\section{SNP genotyping}

In order to validate the imputation results, six top imputed SNPs (rs10447475, rs4621668, rs11215400, rs10926784, rs3196512 and rs7762319) were selected for genotyping using Applied Biosystems TaqMan technology (Life Technologies, Grand Island, NY). One SNP (rs7762319) was not genotyped because the assay failed functional test, and four of the remaining five SNPs were successfully genotyped. Among these four SNPs, rs11215400 was a pre-designed assay, while the remaining three SNPs (rs10447475, rs4621668 and rs10926784) were customized assays designed with Custom TaqMan ${ }^{\circledR}$ Assay Design Tool (Life Technologies, Grand Island, NY). Primer and probe sequences for these assays are available upon request. PCR protocols were followed according to the manufacturer's guidelines for the 384well format. PCR amplifications were performed using Applied Biosystems ${ }^{\circledR}$ TaqMan $^{\circledR}$ Genotyping Master Mix with an Applied Biosystems ${ }^{\circledR}$ Veriti $^{\circledR}$ 384-Well Thermal Cycler (Life Technologies, Grand Island, NY), and PCR products were analyzed on an Applied Biosystems 7900HT [22].

\section{Transient transfection and RNA interference}

Specific siGENOME siRNA SMARTpool ${ }^{\circledR}$ reagents against a given gene, as well as a negative control, siGENOME Non-Targeting siRNA Pool \#2, were purchased from Dharmacon Inc. (Lafayette, CO). Human pancreatic cancer SU86 and breast cancer MDA-MB-231 cell lines were used to perform the siRNA knockdown studies. The lipofectamine RNAiMAX transfection reagent (Invitrogen, Carlsbad, CA) was used for siRNA reverse or forward transfection. Specifically, cells were seeded into 96-well plates and were mixed with siRNA-complex consisting of 20-50 nM of specific siGENOME siRNA SMARTpool or non-targeting negative control (Dharmacon) and the lipofectamine RNAiMAX transfection reagent. The human leukemia cell lines, BDCM and THP-1, were transfected with electroporation using the Nucleofector System with $500 \mathrm{nM}$ of specific or negative siRNA (Lonza Inc., Basel, Switzerland).

\section{Quantitative reverse transcription-PCR (QRT-PCR)}

Total RNA was isolated from cultured cells with the Qiagen RNeasy kit (QIAGEN Inc. Valencia, CA), followed by QRT-PCR performed with the 1-step, Brilliant SYBR Green QRT-PCR master mix kit (Stratagene, La Jolla, CA). Specifically, primers purchased from Qiagen were used to perform QRT-PCR with the Stratagene Mx3005P $\mathrm{P}^{\mathrm{Tw}}$ RealTime PCR detection system (Stratagene). All experiments were performed in triplicate with $\beta$-actin as an internal control. Reverse transcribed Universal Human reference RNA (Stratagene) was used to generate a standard curve. Control reactions lacked RNA template.

\section{Caspase-3/7 activity assay}

Caspase-3/7 activity was measured with the Caspase-Glo ${ }^{\circledR} 3 /$ 7 Assay kit (Promega). Specifically, siRNA-transfected cells (100 $\mathrm{\mu l})$ were seeded overnight into 96-well plates at a 


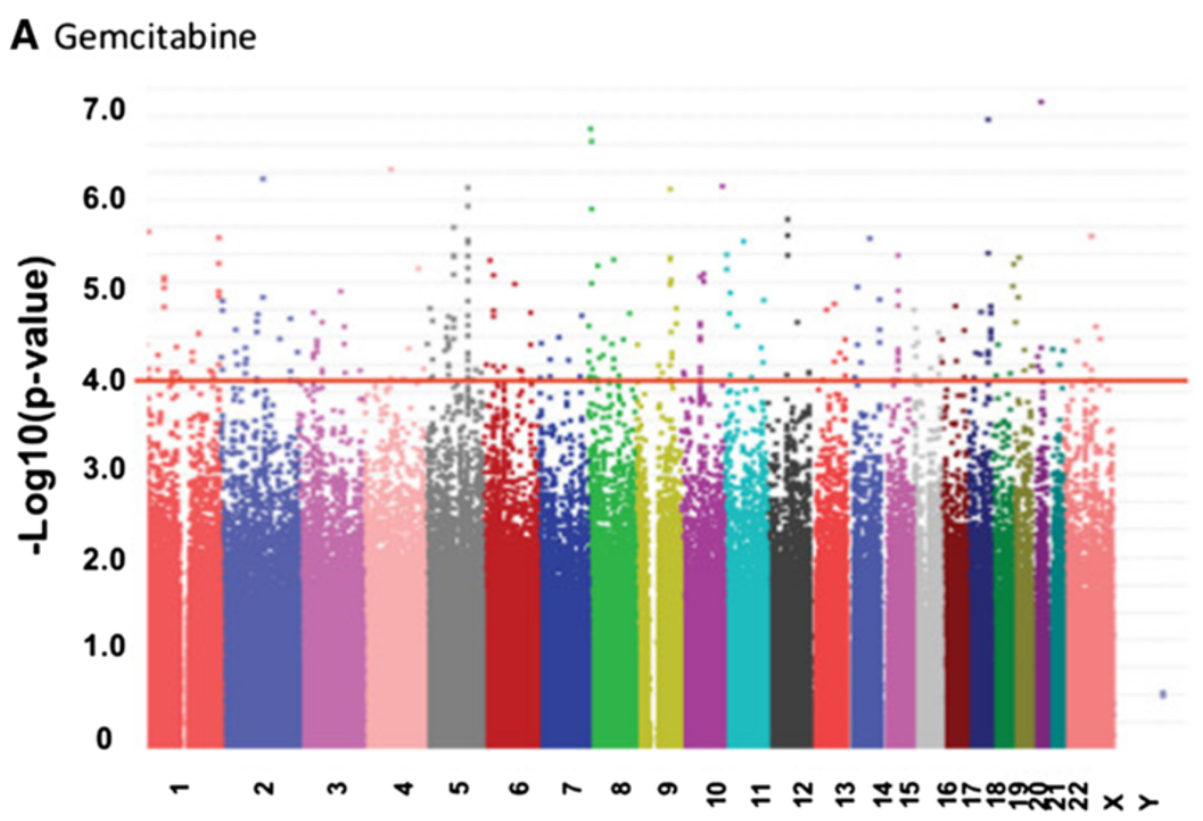

\section{B AraC}

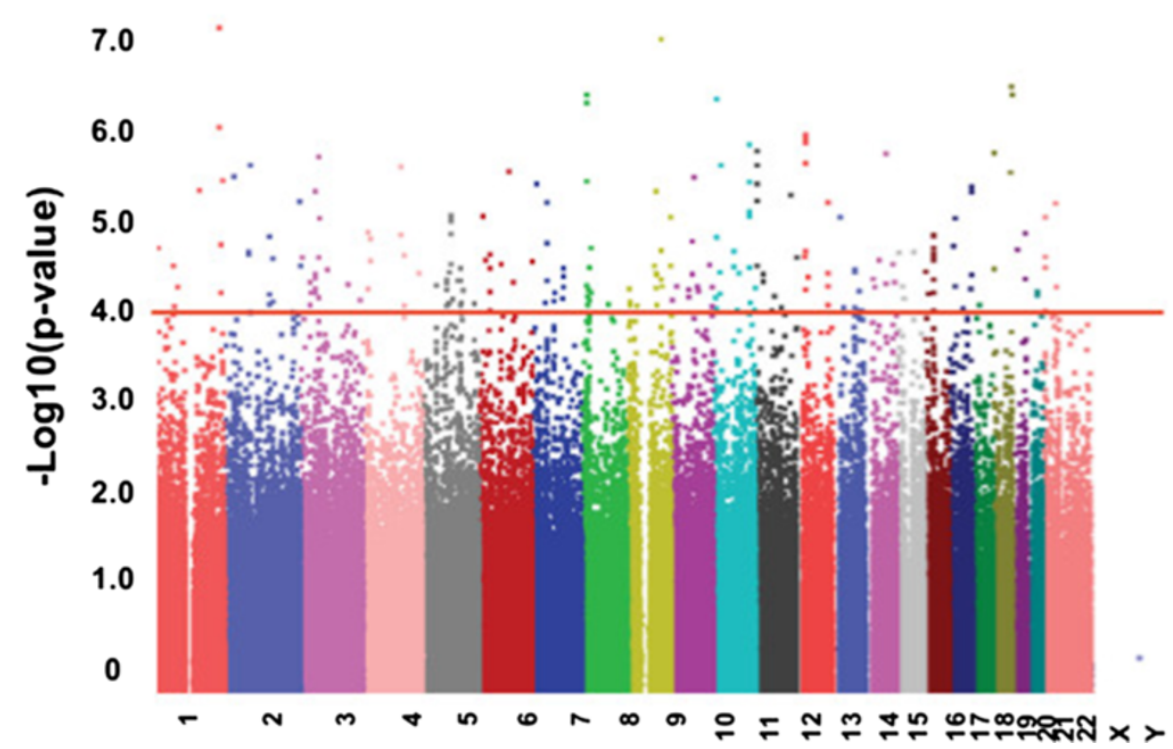

Figure 1 GWAS findings. (A). Manhattan plot of 1.3 million SNPs with gemcitabine IC50 values. (B). Manhattan plot of 1.3 million SNPs with gemcitabine IC50 values. SNPS are plotted on the $\mathrm{x}$-axis based on their chromosomal locations. P values of $10^{-4}$ are highlighted with a red line.

density of 10,000 cells per well and were then treated with DMSO or increasing concentrations of gemcitabine or AraC for 48 h. $100 \mu \mathrm{L}$ of Caspase-Glo ${ }^{\circledR}$ 3/7 Reagent was then added to each well, and the cells were incubated at room temperature for $1 \mathrm{~h}$, followed by the measurement of luminescence with a Safire ${ }^{2}$ microplate reader (Tecan Trading AG, Switzerland). The luminescent signal was proportional to caspase-3/7 activity and was used as a measure of apoptosis. Wells containing only culture medium were used as controls.

\section{Cancer cignal finder 10-pathway reporter array}

The Cignal Finder Arrays consist of 10 dual-luciferase reporter assays for ten cancer-related signaling pathways. Each reporter construct is a mixture of an inducible transcription factor (TF) responsive firefly luciferase reporter and a constitutively expressing Renilla construct at a ratio of 40:1, respectively (SABioscience Co., Frederick, MD). Specifically, cells were reversely transfected with $30 \mathrm{nM}$ of specific siRNA pools in 96-well plates using Lipofectamine RNAiMAX reagent (Invitrogen) 
Table 1 The top 11 loci for Gemcitabine (A) and the top 27 loci for AraC (B) that were associated with drug response-IC50 values

\begin{tabular}{|c|c|c|c|c|c|c|c|c|}
\hline Top SNP rsID & Lowest $\mathbf{R}$ & Lowest $\mathrm{P}$ & Nearby gene & Chr & Position & MAF & Region & Number of SNPs in each locus \\
\hline \multicolumn{9}{|c|}{ (A) Gemcitabine } \\
\hline rs10513968 & -0.382 & $1.04 \mathrm{E}-06$ & DOK6 & 18 & 65434121 & 0.445 & Intron & 9 \\
\hline rs7719624 & -0.370 & 4.22E-06 & TGFBI & 5 & 135405465 & 0.448 & Intron & 28 \\
\hline rs2274870 & 0.362 & 4.33E-06 & NIPSNAP3A & 9 & 106555035 & 0.371 & Coding & 7 \\
\hline rs316838 & -0.345 & $1.21 \mathrm{E}-05$ & PLD5* & 1 & 240387283 & 0.093 & Intron & 12 \\
\hline rs2638094 & -0.339 & $1.72 \mathrm{E}-05$ & ZNF215* & 11 & 6938064 & 0.679 & Flanking_3UTR & 5 \\
\hline rs2290344 & 0.339 & $1.75 \mathrm{E}-05$ & PIGB & 15 & 53407088 & 0.253 & Coding & 9 \\
\hline rs3129890 & 0.332 & 2.67E-05 & $H L A-D R A^{*}$ & 6 & 32522251 & 0.340 & Flanking_3UTR & 23 \\
\hline rs2928445 & -0.331 & $2.76 \mathrm{E}-05$ & IPMK & 10 & 58816782 & 0.267 & Flanking_3UTR & 23 \\
\hline rs4392391 & -0.318 & $5.78 \mathrm{E}-05$ & C3orf23 & 3 & 44247970 & 0.419 & Downstream & 15 \\
\hline rs12522395 & 0.318 & $6.58 \mathrm{E}-05$ & MASS1* & 5 & 90246274 & 0.215 & Intron & 4 \\
\hline rs13171512 & -0.313 & 7.857E-05 & PIK3R1 & 5 & 68000787 & 0.462 & Flanking_3UTR & 4 \\
\hline \multicolumn{9}{|l|}{ (B) AraC } \\
\hline rs10495285 & 0.393 & 4.13E-07 & KIAA0133 (URB2) & 1 & 227871618 & 0.171 & Downstream & 2 \\
\hline rs 1450679 & 0.389 & $5.20 \mathrm{E}-07$ & SMC2L1 & 9 & 106066633 & 0.098 & Flanking_3UTR & 8 \\
\hline rs6128386 & 0.375 & $1.38 \mathrm{E}-06$ & LOC149773 & 20 & 56626955 & 0.466 & Upstream & 4 \\
\hline rs2172820 & -0.373 & $1.63 \mathrm{E}-06$ & TUSC3 & 8 & 15370039 & 0.256 & Flanking_5UTR & 13 \\
\hline rs2857891 & -0.372 & $1.75 \mathrm{E}-06$ & ZNF215* & 11 & 6919533 & 0.101 & Intron & 6 \\
\hline rs9512755 & -0.361 & 3.67E-06 & $L N X 2$ & 13 & 27056229 & 0.055 & Flanking_5UTR & 4 \\
\hline rs888468 & -0.356 & $5.08 \mathrm{E}-06$ & FGF6 & 12 & 4403640 & 0.184 & Flanking_3UTR & 5 \\
\hline rs2653165 & -0.347 & $9.28 \mathrm{E}-06$ & PLD5* & 1 & 240432905 & 0.207 & Intron & 7 \\
\hline rs11215416 & -0.346 & 9.57E-06 & IGSF4 & 11 & 114582537 & 0.147 & Intron & 7 \\
\hline rs10060641 & 0.335 & $1.90 \mathrm{E}-05$ & MASS1* & 5 & 90249006 & 0.216 & Intron & 7 \\
\hline rs5989586 & 0.336 & $1.94 \mathrm{E}-05$ & HDHDIA & 23 & 6757306 & 0.457 & Flanking_3UTR & 8 \\
\hline rs216465 & -0.330 & $2.76 \mathrm{E}-05$ & GOSR1 & 17 & 25880801 & 0.494 & Flanking_3UTR & 12 \\
\hline rs 856548 & -0.326 & 3.29E-05 & TNS3 & 7 & 46730993 & 0.296 & Flanking_3UTR & 8 \\
\hline rs6689258 & 0.325 & $3.40 \mathrm{E}-05$ & GPR137B & 1 & 234362702 & 0.267 & Flanking_5UTR & 2 \\
\hline rs3794794 & -0.325 & $3.61 \mathrm{E}-05$ & $C P D$ & 17 & 25744867 & 0.477 & Intron & 10 \\
\hline rs7192 & 0.322 & 4.10E-05 & $H L A-D R A^{*}$ & 6 & 32519624 & 0.371 & Coding & 11 \\
\hline rs4572738 & 0.322 & $4.45 \mathrm{E}-05$ & CAST1 & 3 & 55799452 & 0.321 & Intron & 8 \\
\hline rs1433446 & 0.319 & 5.05E-05 & TMEM83 & 15 & 85351874 & 0.109 & Flanking_5UTR & 5 \\
\hline rs300962 & 0.320 & 5.47E-05 & LOC51334 & 5 & 119909842 & 0.269 & Intron & 15 \\
\hline rs6441911 & 0.315 & $6.20 \mathrm{E}-05$ & RISI & 3 & 45322523 & 0.055 & Flanking_5UTR & 6 \\
\hline rs1159388 & 0.314 & $6.61 \mathrm{E}-05$ & DCAMKL 1 & 13 & 35544706 & 0.172 & Intron & 11 \\
\hline rs718979 & 0.313 & $6.82 \mathrm{E}-05$ & UBE3A & 15 & 23325370 & 0.394 & Flanking_5UTR & 6 \\
\hline rs1955412 & 0.309 & 8.74E-05 & FLRT2 & 14 & 85082547 & 0.21 & Intron & 11 \\
\hline
\end{tabular}

Each locus contained at least 2 SNPs within $50 \mathrm{~kb}$ with $\mathrm{P}$ values $<10^{-4}$. R values represent correlation coefficients for the association. Number of SNPs indicates the number of significantly associated SNPs in the locus. rsID indicates the most significant SNP associated with drug cytotoxicity in the locus. ${ }^{*}=$ common to both gemcitabine and AraC.

for $24 \mathrm{~h}$, followed by transfection with $100 \mathrm{ng}$ of each reporter construct. Forty-eight $\mathrm{h}$ after the transfection, a dual-luciferase assay was performed with the DualLuciferase Reporter Assay System (Promega) in a Safire ${ }^{2}$ microplate reader (Tecan).

\section{Electrophoresis mobility shift assays (EMSA)}

Based on the genome-wide association results, we performed EMSA for SNPs in potential regulatory regions of genes that were associated with the measured phenotypes. Specifically, double-strand probes were $5^{\prime}$-end 
Table 2 Integrated analyses for drug response for either (A) Gemcitabine or (B) AraC

\begin{tabular}{|c|c|c|c|c|c|c|c|c|c|c|c|c|c|c|}
\hline \multicolumn{6}{|c|}{ SNP } & \multicolumn{3}{|c|}{ Probe set } & \multicolumn{6}{|c|}{ GWAS } \\
\hline rsID & Closest gene & MAF & Chr & Position & Region & Probeset & $\begin{array}{c}\text { Gene } \\
\text { symbol }\end{array}$ & Chr & $\begin{array}{l}\text { R value } \\
\text { (SNP vs } \\
\text { IC50) }\end{array}$ & $\begin{array}{l}\text { P value } \\
\text { (SNP vs } \\
\text { IC50) }\end{array}$ & $\begin{array}{l}\text { R value } \\
\text { (SNP vs } \\
\text { Exp) }\end{array}$ & $\begin{array}{l}\text { P value } \\
\text { (SNP vs } \\
\text { Exp) }\end{array}$ & $\begin{array}{l}R \text { value } \\
\text { (EXP vs } \\
\text { IC50) }\end{array}$ & $\begin{array}{c}\text { P value } \\
\text { (EXP vs } \\
\text { IC50) }\end{array}$ \\
\hline \multicolumn{15}{|c|}{ (A) Gemcitabine } \\
\hline rs316871 & PLD5 & 0.097 & 1 & 240409507 & Intron & 225532_at & CABLES1 & 18 & -0.326 & $4.14 \mathrm{E}-05$ & -0.242 & $6.54 \mathrm{E}-05$ & 0.347 & $3.12 \mathrm{E}-06$ \\
\hline rs316823 & PLD5 & 0.093 & 1 & 240422651 & Intron & 225532_at & CABLES1 & 18 & -0.288 & $2.88 \mathrm{E}-04$ & -0.257 & $2.05 E-05$ & 0.347 & $3.12 \mathrm{E}-06$ \\
\hline rs402098 & PLD5 & 0.093 & 1 & 240430321 & Intron & 225532_at & CABLES1 & 18 & -0.288 & $2.88 \mathrm{E}-04$ & -0.257 & $2.05 E-05$ & 0.347 & $3.12 \mathrm{E}-06$ \\
\hline rs427498 & PLD5 & 0.087 & 1 & 240424078 & Intron & 225532_at & CABLES1 & 18 & -0.280 & 4.43E-04 & -0.256 & $2.28 \mathrm{E}-05$ & 0.347 & $3.12 \mathrm{E}-06$ \\
\hline rs316823 & PLD5 & 0.093 & 1 & 240422651 & Intron & 225531_at & CABLES1 & 18 & -0.288 & $2.88 \mathrm{E}-04$ & -0.239 & 7.69E-05 & 0.321 & $1.72 \mathrm{E}-05$ \\
\hline rs402098 & PLD5 & 0.093 & 1 & 240430321 & Intron & 225531_at & CABLES1 & 18 & -0.288 & $2.88 \mathrm{E}-04$ & -0.239 & 7.69E-05 & 0.321 & $1.72 \mathrm{E}-05$ \\
\hline rs4392391 & C3orf23 & 0.419 & 3 & 44247970 & Downstream & 1555906_s_at & C3orf23 & 3 & -0.318 & $5.78 \mathrm{E}-05$ & -0.250 & $3.46 \mathrm{E}-05$ & 0.263 & 4.86E-04 \\
\hline rs1565214 & C3orf23 & 0.425 & 3 & 44309303 & Upstream & 1555906_s_at & C3orf23 & 3 & -0.308 & $1.35 \mathrm{E}-04$ & -0.251 & 4.09E-05 & 0.263 & $4.86 \mathrm{E}-04$ \\
\hline rs9809107 & C3orf23 & 0.419 & 3 & 44257938 & Flanking_5UTR & 1555906_s_at & C3orf23 & 3 & -0.301 & 1.46E-04 & -0.242 & 5.97E-05 & 0.263 & 4.86E-04 \\
\hline rs967285 & C3orf23 & 0.422 & 3 & 44250280 & Downstream & 1555906_s_at & C3orf23 & 3 & -0.301 & $1.48 \mathrm{E}-04$ & -0.247 & 4.36E-05 & 0.263 & 4.86E-04 \\
\hline rs9821268 & C3orf23 & 0.413 & 3 & 44278128 & Upstream & 1555906_s_at & C3orf23 & 3 & -0.292 & 2.43E-04 & -0.241 & $6.29 \mathrm{E}-05$ & 0.263 & 4.86E-04 \\
\hline rs1565215 & C3orf23 & 0.418 & 3 & 44309103 & Upstream & 1555906_s_at & C3orf23 & 3 & -0.291 & $2.64 \mathrm{E}-04$ & -0.246 & 4.62E-05 & 0.263 & 4.86E-04 \\
\hline rs10510741 & C3orf23 & 0.445 & 3 & 44239198 & Flanking_5UTR & 1555906_s_at & C3orf23 & 3 & -0.283 & $3.68 \mathrm{E}-04$ & -0.275 & $4.71 \mathrm{E}-06$ & 0.263 & 4.86E-04 \\
\hline rs9852733 & C3orf23 & 0.451 & 3 & 44252343 & Flanking_5UTR & 1555906_s_at & C3orf23 & 3 & -0.279 & 4.59E-04 & -0.268 & $8.53 \mathrm{E}-06$ & 0.263 & 4.86E-04 \\
\hline rs6808448 & C3orf23 & 0.451 & 3 & 44218611 & Flanking_5UTR & 1555906_s_at & C3orf23 & 3 & -0.273 & $6.19 \mathrm{E}-04$ & -0.273 & $5.38 \mathrm{E}-06$ & 0.263 & 4.86E-04 \\
\hline rs9846155 & C3orf23 & 0.456 & 3 & 44257844 & Flanking_5UTR & 1555906_s_at & C3orf23 & 3 & -0.272 & $6.33 \mathrm{E}-04$ & -0.262 & $1.38 \mathrm{E}-05$ & 0.263 & 4.86E-04 \\
\hline rs9284879 & C3orf23 & 0.433 & 3 & 44259588 & Flanking_5UTR & 1555906_s_at & C3orf23 & 3 & -0.264 & $9.43 \mathrm{E}-04$ & -0.253 & $2.65 \mathrm{E}-05$ & 0.263 & 4.86E-04 \\
\hline rs12486452 & C3orf23 & 0.433 & 3 & 44299569 & Flanking_5UTR & 1555906_s_at & C3orf23 & 3 & -0.264 & $9.43 \mathrm{E}-04$ & -0.241 & $6.45 \mathrm{E}-05$ & 0.263 & 4.86E-04 \\
\hline rs12631341 & C3orf23 & 0.433 & 3 & 44284272 & Flanking_5UTR & 1555906_s_at & C3orf23 & 3 & -0.264 & $9.43 \mathrm{E}-04$ & -0.241 & $6.45 \mathrm{E}-05$ & 0.263 & 4.86E-04 \\
\hline rs7631790 & C3orf23 & 0.433 & 3 & 44274209 & Flanking_5UTR & 1555906_s_at & C3orf23 & 3 & -0.264 & $9.43 \mathrm{E}-04$ & -0.241 & $6.45 \mathrm{E}-05$ & 0.263 & 4.86E-04 \\
\hline rs4392391 & C3orf23 & 0.419 & 3 & 44247970 & Downstream & 227978_s_at & $\mathrm{ZADH} 2$ & 18 & -0.318 & $5.78 \mathrm{E}-05$ & 0.251 & $3.11 \mathrm{E}-05$ & -0.351 & $2.42 \mathrm{E}-06$ \\
\hline rs1565214 & C3orf23 & 0.425 & 3 & 44309303 & Upstream & 227978_s_at & $\mathrm{ZADH} 2$ & 18 & -0.308 & 1.35E-04 & 0.246 & $5.9 \mathrm{E}-05$ & -0.351 & $2.42 \mathrm{E}-06$ \\
\hline rs9809107 & C3orf23 & 0.419 & 3 & 44257938 & Flanking_5UTR & 227978_s_at & $\mathrm{ZADH} 2$ & 18 & -0.301 & $1.46 \mathrm{E}-04$ & 0.273 & $5.72 \mathrm{E}-06$ & -0.351 & 2.42E-06 \\
\hline rs967285 & C3orf23 & 0.422 & 3 & 44250280 & Downstream & 227978_s_at & $\mathrm{ZADH} 2$ & 18 & -0.301 & $1.48 \mathrm{E}-04$ & 0.254 & $2.58 \mathrm{E}-05$ & -0.351 & $2.42 \mathrm{E}-06$ \\
\hline rs9821268 & C3orf23 & 0.413 & 3 & 44278128 & Upstream & 227978_s_at & $\mathrm{ZADH} 2$ & 18 & -0.292 & $2.43 \mathrm{E}-04$ & 0.247 & 4.17E-05 & -0.351 & $2.42 \mathrm{E}-06$ \\
\hline rs1565215 & C3orf23 & 0.418 & 3 & 44309103 & Upstream & 227978_s_at & $\mathrm{ZADH} 2$ & 18 & -0.291 & 2.64E-04 & 0.250 & $3.46 \mathrm{E}-05$ & -0.351 & $2.42 \mathrm{E}-06$ \\
\hline rs4682949 & C3orf23 & 0.398 & 3 & 44220159 & Flanking_5UTR & 227978_s_at & ZADH2 & 18 & -0.287 & $3.01 \mathrm{E}-04$ & 0.247 & 4.14E-05 & -0.351 & $2.42 \mathrm{E}-06$ \\
\hline rs10510741 & C3orf23 & 0.445 & 3 & 44239198 & Flanking_5UTR & 227978_s_at & $\mathrm{ZADH} 2$ & 18 & -0.283 & $3.68 \mathrm{E}-04$ & 0.251 & 3.03E-05 & -0.351 & $2.42 \mathrm{E}-06$ \\
\hline rs9852733 & C3orf23 & 0.451 & 3 & 44252343 & Flanking_5UTR & 227978_s_at & $\mathrm{ZADH} 2$ & 18 & -0.279 & $4.59 \mathrm{E}-04$ & 0.239 & $7.38 \mathrm{E}-05$ & -0.351 & $2.42 \mathrm{E}-06$ \\
\hline
\end{tabular}


Table 2 Integrated analyses for drug response for either (A) Gemcitabine or (B) AraC (Continued)

\begin{tabular}{|c|c|c|c|c|c|c|c|c|c|c|c|c|c|c|}
\hline rs6808448 & C3orf23 & 0.451 & 3 & 44218611 & Flanking_5UTR & 227978_s_at & $\mathrm{ZADH} 2$ & 18 & -0.273 & $6.19 \mathrm{E}-04$ & 0.260 & $1.62 \mathrm{E}-05$ & -0.351 & $2.42 \mathrm{E}-06$ \\
\hline rs9846155 & C3orf23 & 0.456 & 3 & 44257844 & Flanking_5UTR & 227978_s_at & $\mathrm{ZADH} 2$ & 18 & -0.272 & $6.33 \mathrm{E}-04$ & 0.260 & $1.58 \mathrm{E}-05$ & -0.351 & $2.42 \mathrm{E}-06$ \\
\hline rs12486452 & C3orf23 & 0.433 & 3 & 44299569 & Flanking_5UTR & 227978_s_at & $\mathrm{ZADH} 2$ & 18 & -0.264 & $9.43 \mathrm{E}-04$ & 0.239 & $7.52 \mathrm{E}-05$ & -0.351 & $2.42 \mathrm{E}-06$ \\
\hline rs12631341 & C3orf23 & 0.433 & 3 & 44284272 & Flanking_5UTR & 227978_s_at & $\mathrm{ZADH} 2$ & 18 & -0.264 & $9.43 \mathrm{E}-04$ & 0.239 & $7.52 \mathrm{E}-05$ & -0.351 & $2.42 \mathrm{E}-06$ \\
\hline rs7631790 & C3orf23 & 0.433 & 3 & 44274209 & Flanking_5UTR & 227978_s_at & $\mathrm{ZADH} 2$ & 18 & -0.264 & $9.43 \mathrm{E}-04$ & 0.239 & $7.52 \mathrm{E}-05$ & -0.351 & $2.42 \mathrm{E}-06$ \\
\hline rs12188464 & PIK3RI & 0.459 & 5 & 67999705 & Flanking_5UTR & 225935_at & --- & 7 & -0.309 & $9.69 \mathrm{E}-05$ & 0.366 & $2.47 \mathrm{E}-06$ & -0.296 & $7.99 \mathrm{E}-05$ \\
\hline rs13171512 & $P \mid K 3 R I$ & 0.462 & 5 & 68000787 & Flanking_5UTR & 236170_x_at & --- & 7 & -0.313 & 7.86E-05 & 0.349 & 7.69E-06 & -0.299 & $6.75 \mathrm{E}-05$ \\
\hline rs13171512 & PIK3RI & 0.462 & 5 & 68000787 & Flanking_5UTR & 225935_at & --- & 7 & -0.313 & $7.86 \mathrm{E}-05$ & 0.375 & $1.33 \mathrm{E}-06$ & -0.296 & $7.99 \mathrm{E}-05$ \\
\hline rs7713001 & PIK3RI & 0.459 & 5 & 67999371 & Flanking_5UTR & 225935_at & --- & 7 & -0.309 & $9.69 \mathrm{E}-05$ & 0.366 & $2.47 \mathrm{E}-06$ & -0.296 & 7.99E-05 \\
\hline rs12188464 & PIK3RI & 0459 & 5 & 67999705 & Flanking_5UTR & 201334_s_at & ARHGEF12 & 11 & -0.309 & $9.69 \mathrm{E}-05$ & 0.380 & $9.03 \mathrm{E}-07$ & -0.339 & $5.35 \mathrm{E}-06$ \\
\hline rs13171512 & PIK3RI & 0.462 & 5 & 68000787 & Flanking_5UTR & 201334_s_at & ARHGEF12 & 11 & -0.313 & $7.86 \mathrm{E}-05$ & 0.372 & $1.59 \mathrm{E}-06$ & -0.339 & $5.35 \mathrm{E}-06$ \\
\hline rs7713001 & PIK3RI & 0.459 & 5 & 67999371 & Flanking_5UTR & 201334_s_at & ARHGEF12 & 11 & -0.309 & $9.69 \mathrm{E}-05$ & 0.380 & $9.03 \mathrm{E}-07$ & -0.339 & $5.35 \mathrm{E}-06$ \\
\hline rs12188464 & PIK3RI & 0.459 & 5 & 67999705 & Flanking_3UTR & 238012_at & DPP7 & 9 & -0.309 & $9.69 \mathrm{E}-05$ & 0.372 & $1.63 \mathrm{E}-06$ & -0.324 & 1.45E-05 \\
\hline rs13171512 & PIK3RI & 0.462 & 5 & 68000787 & Flanking_3UTR & 238012_at & DPP7 & 9 & -0.313 & 7.86E-05 & 0.378 & $1.08 \mathrm{E}-06$ & -0.324 & 1.45E-05 \\
\hline rs7713001 & PIK3RI & 0.459 & 5 & 67999371 & Flanking_3UTR & 238012_at & DPP7 & 9 & -0.309 & $9.69 \mathrm{E}-05$ & 0.372 & $1.63 \mathrm{E}-06$ & -0.324 & $1.45 \mathrm{E}-05$ \\
\hline rs12188464 & PIK3RI & 0.459 & 5 & 67999705 & Flanking_3UTR & 225086_at & FAM98B & 15 & -0.309 & $9.69 \mathrm{E}-05$ & 0.345 & $9.5 \mathrm{E}-06$ & -0.352 & $2.18 \mathrm{E}-06$ \\
\hline rs13171512 & PIK3RI & 0.462 & 5 & 68000787 & Flanking_3UTR & 225086_at & FAM98B & 15 & -0.313 & 7.86E-05 & 0.354 & $5.38 \mathrm{E}-06$ & -0.352 & $2.18 \mathrm{E}-06$ \\
\hline rs3135351 & HLA-DRA & 0.137 & 6 & 32500923 & Flanking_5UTR & 1566082_at & --- & 10 & 0.265 & $9.48 \mathrm{E}-04$ & 0.277 & 4.24E-06 & 0.320 & $1.88 \mathrm{E}-05$ \\
\hline rs2472476 & NIPSNAP3B & 0.389 & 9 & 106571777 & Intron & 200988_s_at & PSME3 & 17 & 0.338 & $1.92 \mathrm{E}-05$ & -0.239 & 7.6E-05 & -0.350 & $.60 \mathrm{E}-06$ \\
\hline rs2928445 & IPMK & 0.267 & 10 & 58816782 & Flanking_3UTR & 227482_at & $A D C K 1$ & 14 & -0.331 & $2.76 \mathrm{E}-05$ & 0.247 & 4.09E-05 & -0.293 & 9.45E-05 \\
\hline rs12244977 & IPMK & 0.195 & 10 & 58762688 & Flanking_3UTR & 1569396_at & $R A B 40 C$ & 16 & -0.308 & $1.03 \mathrm{E}-04$ & -0.243 & $5.72 \mathrm{E}-05$ & 0.303 & 5.47E-05 \\
\hline rs12256364 & IPMK & 0.195 & 10 & 58765694 & Flanking_3UTR & 1569396_at & RABAOC & 16 & -0.308 & $1.03 \mathrm{E}-04$ & -0.243 & $5.72 \mathrm{E}-05$ & 0.303 & 5.47E-05 \\
\hline rs2928445 & IPMK & 0.267 & 10 & 58816782 & Flanking_3UTR & 226987_at & RBM15B & 3 & -0.331 & $2.76 \mathrm{E}-05$ & 0.263 & $1.2 \mathrm{E}-05$ & -0.354 & $1.90 \mathrm{E}-06$ \\
\hline rs4774760 & $P I G B$ & 0.416 & 15 & 53376504 & upstreaintronm & 224856_at & FKBP5 & 6 & 0.326 & $3.63 \mathrm{E}-05$ & -0.241 & $6.7 \mathrm{E}-05$ & -0.411 & $2.15 \mathrm{E}-08$ \\
\hline rs7174876 & $P I G B$ & 0.416 & 15 & 53406853 & Upstream & 224856_at & FKBP5 & 6 & 0.284 & 4.06E-04 & -0.237 & $9.71 \mathrm{E}-05$ & -0.411 & $2.15 \mathrm{E}-08$ \\
\hline rs2290344 & $P I G B$ & 0.253 & 15 & 53407088 & Coding & 224856_at & FKBP5 & 6 & 0.339 & 1.75E-05 & -0.266 & 9.87E-06 & -0.393 & $9.66 \mathrm{E}-08$ \\
\hline rs4774760 & $P I G B$ & 0.416 & 15 & 53376504 & Upstream & 204560_at & FKBP5 & 6 & 0.326 & $3.63 \mathrm{E}-05$ & -0.282 & 2.7E-06 & -0.393 & 9.66E-08 \\
\hline rs12050587 & $P I G B$ & 0.45 & 15 & 53414820 & Intron & 224856_at & FKBP5 & 6 & 0.305 & 1.23E-04 & -0.256 & $2.27 \mathrm{E}-05$ & -0.393 & $9.66 \mathrm{E}-08$ \\
\hline rs28668016 & $P I G B$ & 0.365 & 15 & 53398725 & 5UTR & 204560_at & FKBP5 & 6 & 0.304 & $1.31 \mathrm{E}-04$ & -0.261 & 1.49E-05 & -0.393 & $9.66 \mathrm{E}-08$ \\
\hline rs11636687 & $P I G B$ & 0.421 & 15 & 53392444 & Flanking_5UTR & 224856_at & FKBP5 & 6 & 0.302 & $1.53 \mathrm{E}-04$ & -0.252 & $3.34 \mathrm{E}-05$ & -0.393 & $9.66 \mathrm{E}-08$ \\
\hline rs2414409 & $P I G B$ & 0.448 & 15 & 53419009 & Intron & 204560_at & FKBP5 & 6 & 0.299 & $1.62 \mathrm{E}-04$ & -0.264 & 1.17E-05 & -0.393 & $9.66 \mathrm{E}-08$ \\
\hline rs7183960 & $P I G B$ & 0.451 & 15 & 53409987 & Intron & 224856_at & FKBP5 & 6 & 0.292 & $2.37 \mathrm{E}-04$ & -0.262 & 1.37E-05 & -0.393 & $9.66 \mathrm{E}-08$ \\
\hline rs7174876 & $P I G B$ & 0.423 & 15 & 53406853 & Intron & 204560_at & FKBP5 & 6 & 0.284 & 4.06E-04 & -0.274 & $6.06 \mathrm{E}-06$ & -0.393 & $9.66 \mathrm{E}-08$ \\
\hline
\end{tabular}


Table 2 Integrated analyses for drug response for either (A) Gemcitabine or (B) AraC (Continued)

\begin{tabular}{|c|c|c|c|c|c|c|c|c|c|c|c|c|c|c|}
\hline rs2290344 & $P I G B$ & 0.253 & 15 & 53407088 & Coding & 224856_at & $P I G B$ & 15 & 0.339 & $1.75 \mathrm{E}-05$ & -0.301 & $4.81 \mathrm{E}-07$ & -0.294 & $8.98 \mathrm{E}-05$ \\
\hline rs4774760 & $P I G B$ & 0.416 & 15 & 53376504 & Upstream & 242760_x_at & $P I G B$ & 15 & 0.326 & $3.63 \mathrm{E}-05$ & -0.240 & $6.85 E-05$ & -0.294 & $8.98 \mathrm{E}-05$ \\
\hline rs8024695 & $P I G B$ & 0.285 & 15 & 53426597 & Intron & 242760_x_at & PIGB & 15 & 0.321 & $5.00 \mathrm{E}-05$ & -0.282 & $2.56 \mathrm{E}-06$ & -0.294 & $8.98 \mathrm{E}-05$ \\
\hline rs28668016 & $P I G B$ & 0.365 & 15 & 53398725 & 5UTR & 242760_x_at & $P I G B$ & 15 & 0.304 & $1.31 \mathrm{E}-04$ & -0.274 & $5.28 \mathrm{E}-06$ & -0.294 & $8.98 \mathrm{E}-05$ \\
\hline \multicolumn{15}{|l|}{ (B) AraC } \\
\hline rs10495285 & KIAA0133 (URB2) & 0.171 & 1 & 227871618 & Downstream & 219526_at & C14orf169 & 14 & 0.393 & $4.13 \mathrm{E}-07$ & -0.240 & 6.97E-05 & -0.318 & $1.86 \mathrm{E}-05$ \\
\hline rs9861198 & $\begin{array}{l}\text { Probable leucyl- } \\
\text { tRNA synthetase }\end{array}$ & 0.086 & 3 & 45310394 & Upstream & 235936_at & LOC254559 & 15 & 0.308 & 9.07E-05 & 0.274 & $5.12 \mathrm{E}-06$ & 0.294 & $8.27 \mathrm{E}-05$ \\
\hline rs9816196 & $\begin{array}{c}\text { U3 small } \\
\text { nucleolar RNA }\end{array}$ & 0.055 & 3 & 45321382 & Upstream & 235936_at & LOC254559 & 15 & 0.315 & $6.70 \mathrm{E}-05$ & 0.242 & 7.05E-05 & 0.294 & $8.27 \mathrm{E}-05$ \\
\hline rs6441911 & RIST & 0.055 & 3 & 45322523 & Flanking_5UTR & 235936_at & LOC254559 & 15 & 0.315 & $6.20 \mathrm{E}-05$ & 0.250 & $3.26 \mathrm{E}-05$ & 0.294 & $8.27 \mathrm{E}-05$ \\
\hline rs9878275 & $\begin{array}{l}\text { Probable leucyl- } \\
\text { tRNA synthetase }\end{array}$ & 0.055 & 3 & 45331043 & Upstream & 235936_at & LOC254559 & 15 & 0.311 & 8.31E-05 & 0.249 & 3.79E-05 & 0.294 & $8.27 \mathrm{E}-05$ \\
\hline rs9846284 & $\begin{array}{c}\text { U3 small } \\
\text { nucleolar RNA }\end{array}$ & 0.055 & 3 & 45331970 & Upstream & 235936_at & LOC254559 & 15 & 0.315 & $6.20 \mathrm{E}-05$ & 0.250 & 3.37E-05 & 0.294 & $8.27 \mathrm{E}-05$ \\
\hline rs9850725 & LARS2 & 0.055 & 3 & 45332431 & Flanking_5UTR & 235936_at & LOC254559 & 15 & 0.315 & $6.20 \mathrm{E}-05$ & 0.250 & $3.26 \mathrm{E}-05$ & 0.294 & $8.27 \mathrm{E}-05$ \\
\hline rs9861198 & $\begin{array}{l}\text { Probable leucyl- } \\
\text { tRNA synthetase }\end{array}$ & 0.086 & 3 & 45310394 & Upstream & 206603_at & SLC2A4 & 17 & 0.308 & $9.07 \mathrm{E}-05$ & 0.239 & 7.63E-05 & 0.345 & $3.18 \mathrm{E}-06$ \\
\hline rs9816196 & $\begin{array}{c}\text { U3 small } \\
\text { nucleolar RNA }\end{array}$ & 0.055 & 3 & 45321382 & Upstream & 206603_at & $S L C 2 A 4$ & 17 & 0.315 & $6.70 \mathrm{E}-05$ & 0.294 & $1.21 \mathrm{E}-06$ & 0.345 & $3.18 \mathrm{E}-06$ \\
\hline rs6441911 & RIST & 0.055 & 3 & 45322523 & Flanking_5UTR & 206603_at & SLC2A4 & 17 & 0.315 & $6.20 \mathrm{E}-05$ & 0.301 & 4.80E-07 & 0.345 & $3.18 \mathrm{E}-06$ \\
\hline rs9878275 & $\begin{array}{l}\text { Probable leucyl- } \\
\text { tRNA synthetase }\end{array}$ & 0.055 & 3 & 45331043 & Upstream & 206603_at & SLC2A4 & 17 & 0.311 & $8.31 \mathrm{E}-05$ & 0.300 & 5.67E-07 & 0.345 & $3.18 \mathrm{E}-06$ \\
\hline rs9846284 & $\begin{array}{c}\text { U3 small } \\
\text { nucleolar RNA }\end{array}$ & 0.055 & 3 & 45331970 & Upstream & 206603_at & SLC2A4 & 17 & 0.315 & $6.20 \mathrm{E}-05$ & 0.301 & 5.03E-07 & 0.345 & $3.18 \mathrm{E}-06$ \\
\hline rs9850725 & LARS2 & 0.055 & 3 & 45332431 & Flanking_5UTR & 206603_at & $S L C 2 A 4$ & 17 & 0.315 & $6.20 \mathrm{E}-05$ & 0.301 & 4.80E-07 & 0.345 & $3.18 \mathrm{E}-06$ \\
\hline rs9816196 & $\begin{array}{c}\text { U3 small } \\
\text { nucleolar RNA }\end{array}$ & 0.055 & 3 & 45321382 & Upstream & 1553755_at & NXNL1 & 19 & 0.315 & $6.70 \mathrm{E}-05$ & 0.237 & $9.98 \mathrm{E}-05$ & 0.312 & $2.82 \mathrm{E}-05$ \\
\hline rs6441911 & RIST & 0.055 & 3 & 45322523 & Flanking_5UTR & 1553755_at & NXNL1 & 19 & 0.315 & $6.20 \mathrm{E}-05$ & 0.245 & 4.73E-05 & 0.312 & $2.82 \mathrm{E}-05$ \\
\hline rs9878275 & $\begin{array}{l}\text { Probable leucyl- } \\
\text { tRNA synthetase }\end{array}$ & 0.055 & 3 & 45331043 & Upstream & 1553755_at & NXNL1 & 19 & 0.311 & $8.31 \mathrm{E}-05$ & 0.244 & $5.26 \mathrm{E}-05$ & 0.312 & $2.82 \mathrm{E}-05$ \\
\hline rs9846284 & $\begin{array}{c}\text { U3 small } \\
\text { nucleolar RNA }\end{array}$ & 0.055 & 3 & 45331970 & Upstream & 1553755_at & NXNL1 & 19 & 0.315 & $6.20 \mathrm{E}-05$ & 0.245 & $4.88 \mathrm{E}-05$ & 0.312 & $2.82 \mathrm{E}-05$ \\
\hline rs9850725 & LARS2 & 0.055 & 3 & 45332431 & Flanking_5UTR & 1553755_at & NXNL1 & 19 & 0.315 & $6.20 \mathrm{E}-05$ & 0.245 & 4.73E-05 & 0.312 & $2.82 \mathrm{E}-05$ \\
\hline rs17564430 & IGSF4 (CADM1) & 0.155 & 11 & 114548784 & Flanking_3UTR & 206571_s_at & MAP4K4 & 2 & -0.337 & $1.74 \mathrm{E}-05$ & 0.237 & $8.48 \mathrm{E}-05$ & -0.322 & $1.51 \mathrm{E}-05$ \\
\hline rs11215406 & IGSF4 (CADM1) & 0.138 & 11 & Intron 114570292 & Intron & 206571_s_at & MAP4K4 & 2 & -0.335 & $1.92 \mathrm{E}-05$ & 0.248 & $3.93 \mathrm{E}-05$ & -0.322 & $1.51 \mathrm{E}-05$ \\
\hline rs11215406 & IGSF4 (CADM1) & 0.138 & 11 & 114570292 & Intron & 204201_s_at & PTPN13 & 4 & -0.335 & $1.92 \mathrm{E}-05$ & 0.243 & 5.49E-05 & -0.301 & $5.30 \mathrm{E}-05$ \\
\hline
\end{tabular}


Table 2 Integrated analyses for drug response for either (A) Gemcitabine or (B) AraC (Continued)

\begin{tabular}{|c|c|c|c|c|c|c|c|c|c|c|c|c|c|c|}
\hline rs17564430 & IGSF4 (CADM1) & 0.155 & 11 & 114548784 & Flanking_3UTR & 204880_at & MGMT & 10 & -0.337 & $1.74 \mathrm{E}-05$ & -0.236 & $9.07 \mathrm{E}-05$ & 0.332 & $7.44 \mathrm{E}-06$ \\
\hline rs17564430 & IGSF4 (CADM1) & 0.155 & 11 & 114548784 & Flanking_3UTR & 1556095_at & UNC13C & 15 & -0.337 & $1.74 \mathrm{E}-05$ & 0.256 & $2.21 \mathrm{E}-05$ & -0.354 & 1.60E-06 \\
\hline rs17564430 & IGSF4 (CADM1) & 0.155 & 11 & 114548784 & Flanking_3UTR & 1556096_s_at & UNC13C & 15 & -0.337 & $1.74 \mathrm{E}-05$ & 0.240 & 7.07E-05 & -0.337 & 5.47E-06 \\
\hline rs17564430 & IGSF4 (CADM1) & 0.155 & 11 & 114548784 & Flanking_3UTR & 1569969_a_at & UNC13C & 15 & -0.337 & $1.74 \mathrm{E}-05$ & 0.257 & $1.93 \mathrm{E}-05$ & -0.332 & $7.56 \mathrm{E}-06$ \\
\hline rs11215406 & IGSF4 (CADM1) & 0.138 & 11 & 114570292 & Intron & 1556095_at & UNC13C & 15 & -0.335 & $1.92 \mathrm{E}-05$ & 0.276 & 4.27E-06 & -0.354 & 1.60E-06 \\
\hline rs11215406 & IGSF4 (CADM1) & 0.138 & 11 & 114570292 & Intron & 1556096_s_at & UNC13C & 15 & -0.335 & $1.92 \mathrm{E}-05$ & 0.255 & $2.29 \mathrm{E}-05$ & -0.337 & 5.47E-06 \\
\hline rs11215406 & IGSF4 (CADM1) & 0.138 & 11 & 114570292 & Intron & 1569969_a_at & UNC13C & 15 & -0.335 & $1.92 \mathrm{E}-05$ & 0.270 & $7.08 \mathrm{E}-06$ & -0.332 & $7.56 \mathrm{E}-06$ \\
\hline rs11215416 & IGSF4 (CADM1) & 0.147 & 11 & 114582537 & Intron & 1556095_at & UNC13C & 15 & -0.346 & $9.57 \mathrm{E}-06$ & 0.260 & $1.59 \mathrm{E}-05$ & -0.354 & 1.60E-06 \\
\hline rs11215416 & IGSF4 (CADM1) & 0.147 & 11 & 114582537 & Intron & 1556096_s_at & UNC13C & 15 & -0.346 & 9.57E-06 & 0.242 & $6.21 \mathrm{E}-05$ & -0.337 & 5.47E-06 \\
\hline rs11215416 & IGSF4 (CADM1) & 0.147 & 11 & 114582537 & Intron & 1569969_a_at & UNC13C & 15 & -0.346 & 9.57E-06 & 0.258 & $1.84 \mathrm{E}-05$ & -0.332 & $7.56 \mathrm{E}-06$ \\
\hline rs2008801 & IGSF4 (CADM1) & 0.126 & 11 & 114513385 & Flanking_3UTR & 225532_at & CABLESI & 18 & -0.317 & $5.42 \mathrm{E}-05$ & -0.254 & $2.54 \mathrm{E}-05$ & 0.271 & $2.92 \mathrm{E}-04$ \\
\hline rs2507905 & IGSF4 (CADM1) & 0.126 & 11 & 114513815 & Downstream & 225532_at & CABLES1 & 18 & -0.317 & $5.42 \mathrm{E}-05$ & -0.254 & $2.54 \mathrm{E}-05$ & 0.271 & $2.92 \mathrm{E}-04$ \\
\hline rs7122402 & IGSF4 (CADM1) & 0.126 & 11 & 114521517 & Downstream & 225532_at & CABLES1 & 18 & -0.317 & $5.42 \mathrm{E}-05$ & -0.261 & $1.43 \mathrm{E}-05$ & 0.271 & $2.92 \mathrm{E}-04$ \\
\hline rs4938179 & IGSF4 (CADM1) & 0.132 & 11 & 114538635 & Downstream & 225532_at & CABLES1 & 18 & -0.289 & $2.56 \mathrm{E}-04$ & -0.247 & 4.34E-05 & 0.271 & $2.92 \mathrm{E}-04$ \\
\hline rs17564430 & IGSF4 (CADM1) & 0.155 & 11 & 114548784 & Flanking_3UTR & 225532_at & CABLES1 & 18 & -0.337 & $1.74 \mathrm{E}-05$ & -0.242 & $6.19 \mathrm{E}-05$ & 0.271 & $2.92 \mathrm{E}-04$ \\
\hline
\end{tabular}

"Integrated analyses" with the top expression probe sets that were associated with SNPs within loci with gemcitabine IC50 (SNP vs. Expression P value $<10^{-4}$, and Expression vs. IC50 P value $<10^{-4}$ ), except for C3orf23 (SNP vs. Expression P value $<10^{-4}$, and Expression vs. IC50 P value $\approx 10^{-4}$ ). Eighteen unique probe sets, representing 12 annotated genes that were associated with 66 SNPs within 7 loci and were significantly

correlated with gemcitabine IC50 values are listed. (B) "Integrated analyses" for AraC. Eleven unique probe sets, representing 6 annotated genes that were associated with 15 SNPs within 3 loci and were significantly correlated with AraC IC50 values are listed. R values represent correlation coefficients for each association. 
Table 3 Functional studies of candidate genes

\begin{tabular}{|c|c|c|c|c|c|}
\hline \multirow[t]{3}{*}{ Gene symbol } & \multicolumn{3}{|l|}{ Selection strategy } & \multicolumn{2}{|c|}{ Cytotoxicity validation in cancer cell lines } \\
\hline & \multicolumn{2}{|l|}{ SNP vs. IC50 } & \multirow{3}{*}{$\begin{array}{l}\text { Integrated analysis } \\
\text { SNP vs. Exp } P<10-4 \\
\text { Exp vs. IC50 } P<10-4\end{array}$} & \multirow{3}{*}{$\begin{array}{l}\text { Both SU86 and MDA231 } \\
\text { (cancer cell lines) }\end{array}$} & \multirow{3}{*}{$\begin{array}{l}\text { Either THP-1 or BDCM } \\
\text { (leukemia cell lines) }\end{array}$} \\
\hline & SNP Location & $\mathrm{P}<10-4$ & & & \\
\hline & & & & & \\
\hline$\overline{P I G B}$ & Intron/coding/5UTR/3UTR & Gem & Gem & Yes & NP \\
\hline C3orf23 & 5UTR/upstream & Gem & Gem & No & NP \\
\hline $\mathrm{ZADH} 2$ & & & Gem & Yes & NP \\
\hline ARHGEF12 & & & Gem & No & NP \\
\hline DPP7 & & & Gem & No & NP \\
\hline PSME3 & & & Gem & Yes & NP \\
\hline NIPSNAP3B & Intron/5UTR & Gem & & No & NP \\
\hline PIK3R1 & Flanking_5UTR/3UTR & Gem & & No & NP \\
\hline DOK6 & Intron & Gem & & Yes & NP \\
\hline$T G F B I$ & Flanking_5UTR & Gem & & Yes & NP \\
\hline UNC13C & & & AraC & No & No \\
\hline C14orf169 & & & AraC & Yes & NP \\
\hline MAP4K4 & & & AraC & No & NP \\
\hline URB2 & Downstream & AraC & & No & No \\
\hline TUSC3 & Intron/5UTR/3UTR & AraC & & Yes & No \\
\hline LARS2 & 5UTR & AraC & & Yes & No \\
\hline RIS1 (TMEM158) & 5UTR & AraC & & Yes & Yes \\
\hline IGSF4 (CADM1) & Intron/downstream/3UTR & AraC & & No & No \\
\hline$L N X 2$ & Intron/5UTR/3UTR & AraC & & Yes & No \\
\hline$S M C 2$ & 3UTR & AraC & & Yes & Yes \\
\hline PLD5 & Intron & Both & & No & NP \\
\hline GPR98 & Intron & Both & & No & No \\
\hline$H L A-D R A$ & Intron/3UTR & Both & & Yes & No \\
\hline ZNF215 & Flanking_5UTR/3UTR/coding & Both & & No & No \\
\hline CABLES1 & & & Both & No & No \\
\hline
\end{tabular}

The table lists the top 26 candidate genes selected for siRNA screening for both gemcitabine and AraC, with MTS assay results as well as QRT-PCR assay results when appropriate.

A total of 26 genes were selected for siRNA screening, with 11 genes for gemcitabine, 10 for AraC, and 5 for both. For the validation assays with MTS and QRT-PCR, "Yes" indicates that knockdown of the gene altered drug cytotoxicity, while "No" indicates no alteration. "NP" indicates not performed. The genes that are bolded were functionally validated.

labeled with biotin and electrophoresis was performed with 5\% acrylamide gels, followed by autoradiography. Competition experiments were performed with excess non-labeled probe.

\section{Genome-wide gene expression and SNP analysis}

Expression array data were obtained for all 174 lymphoblastoid cell lines (LCLs) as previously described [17]. Illumina HumanHap550K and 510S BeadChips, which assayed 561,298 and 493,750 SNPs, respectively, were used to obtain genome-wide SNP data for these LCLs [23]. Genotyping was performed in the Genotype Shared Resource (GSR) at the Mayo Clinic, Rochester, MN. We also obtained publicly available Affymetrix SNP Array
6.0 Chip SNP data which involved 643,600 SNPs unique to the Affymetrix SNP array for the same cell lines. After quality control (QC), SNPs with call rates $<0.95$, HardyWeinberg Equilibrium (HWE) P values $<0.001$, or MAFs $<5 \%$ were excluded, as were DNA samples with call rates $<0.95$. A total of $1,348,798$ SNPs that passed QC were used to perform the association studies.

\section{Imputation analysis}

SNPs not genotyped were imputed across a region $200 \mathrm{~kb}$ up or downstream of the selected genes harboring or close to the SNPs associated with drug response in the LCLs. Imputation was performed using Beagle (v3.3.1) [24] with the $11 / 23 / 2010$ release of the 1000 


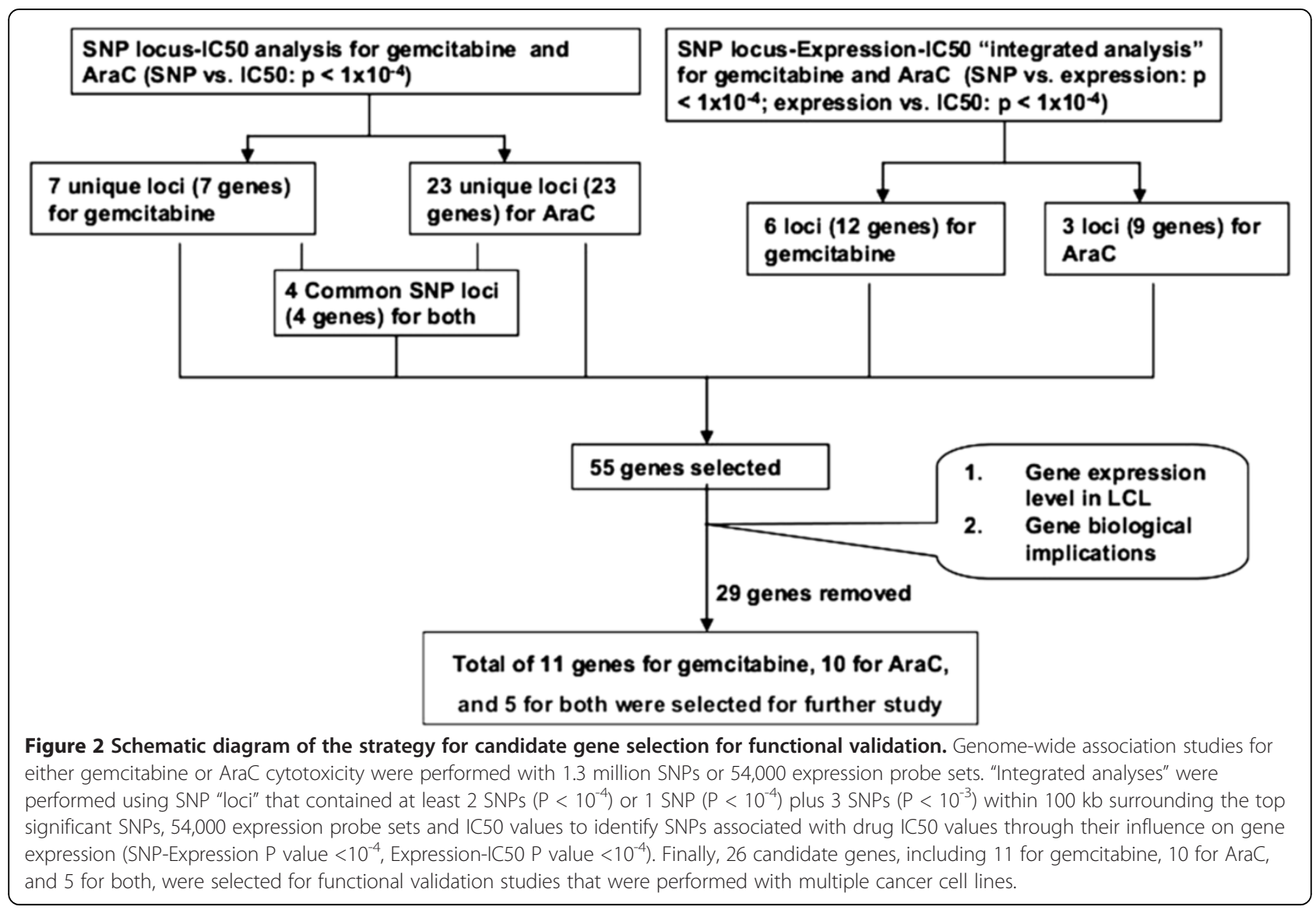

Genomes project as a reference population [25]. Imputed SNPs with a dosage $R^{2}$ quality measure of less than 0.3, and SNPs with MAF $<0.01$ were not included in the analysis. Four of the imputed SNPs were genotyped for validation, the average squared difference between the count of the same allele in the imputed and genotyped version of these SNPs was computed to measure the concordance of the imputed genotype with actual genotype, a smaller difference indicating greater concordance.

\section{Statistical methods}

Partial Pearson correlations were used to quantify the association between: SNPs and mRNA expression; SNPs and $\mathrm{IC}_{50}$; and mRNA expression and $\mathrm{IC}_{50} . \mathrm{IC}_{50}$ was transformed to remove skewness using a log transformation for gemcitabine and van der Waerden rank transformation for AraC. The adjustment variables in the partial correlation were race and gender if SNPs were not involved; or race, gender and five eigenvectors controlling for population stratification as described previously [23]. These partial correlations were tested using a Wald test, false discovery q-values [26] were also computed for each test.

\section{Results}

Genome-wide SNP vs. drug cytotoxicity association study and imputation analysis

Previously, we had performed GWAS using only the $550 \mathrm{k}$ SNP data set for this cell line system [18]. In the current study, we expand the SNPs studies to include additional Illumina SNPs as well as publically available SNP data obtained with Affymetrix 6.0 SNP data for the same cell lines to identify additional novel potential pharmacogenomic biomarkers. As a result, we performed an analysis for the association of 1,348,798 SNPs with IC50 values for gemcitabine and AraC (Figure 1A and 1B). The most significant SNP for gemcitabine was rs1598848 with a $\mathrm{P}$ value $7.08 \times 10^{-7}(\mathrm{r}=-0.391, \mathrm{MAF}=$ 0.473), while the most significant SNP for AraC was rs4078252 with a $\mathrm{P}$ value $1.54 \times 10^{-7}(\mathrm{r}=0.405, \mathrm{MAF}=$ 0.198) (Additional file 1: Table S1A and B). Fourteen SNPs for gemcitabine and 34 for AraC had $\mathrm{P}$ values $<10^{-5}$, and 143 SNPs for gemcitabine and 204 SNPs for AraC had P values $<10^{-4}$, respectively. One hundred and twenty six SNPs with $\mathrm{P}<10^{-3}$ were common to both drugs (Additional file 1: Table S1C). To explore ungenotyped SNPs that might be functional, we imputed SNPs surrounding the selected genes $(+/-200 \mathrm{~kb})$ harboring or close to the most significant SNP loci using 1000 


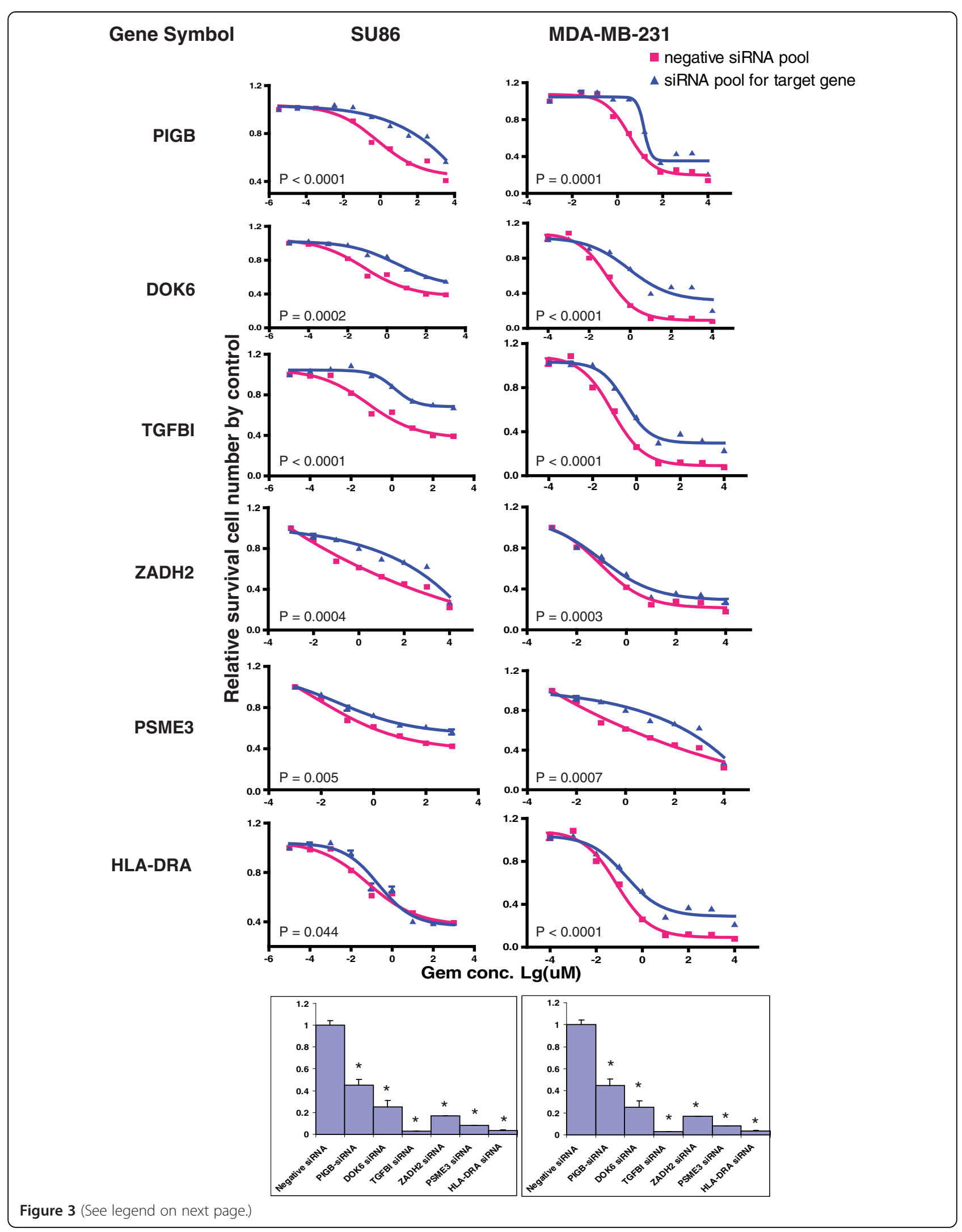


Figure 3 Functional characterization of candidate genes. Knockdown of individual genes in cancer cell lines followed by MTS assays to determine the effect of the candidate gene on gemcitabine. Data are shown for 11 validated out of the 26 candidate genes tested in SU86, MDA-MB-231, BDCM, and THP-1 cancer cell lines by MTS assay after siRNA knockdown performed with a pool of 4 specific siRNAs. The drug dose response curves were obtained with the MTS assays. Red lines indicate the negative control siRNA pool, while blue lines indicate data obtained with specific siRNA pool. The $x$-axis indicates the $\log 10$ gemcitabine concentration and the $y$-axis indicates the proportion of cells surviving after drug exposure. The bar graphs at the bottom show knockdown efficiency tested by QRT-PCR assay using the same transfected cells as those used to perform the MTS assays. The $y$-axis indicates relative gene expression after siRNA knockdown when compared with negative control siRNA.

The experiments were repeated 3 times and the error bar represents SEM. Each of the genes was significantly knocked down when compared to the negsiRNA control, $\mathrm{P}<0.05$.

Genomes data as a reference (Additional file 1: Figure $\mathrm{S} 1 \mathrm{~A}, \mathrm{~B}$, and C). Besides the "observed SNPs" on the genotyping platforms, there were 23 imputed SNPs for gemcitabine and 35 for $\mathrm{AraC}$, respectively, that were also associated with drug response IC50 values $\left(\mathrm{P}<10^{-4}\right)$ (Additional file 1: Table S2A and B). In order to determine the accuracy of imputation, we selected 6 imputed SNPs (rs10447475, rs4621668, rs11215400, rs10926784, rs3196512 and rs7762319) that were among the top two SNPs from each gene region associated with drug response IC50s $\left(\mathrm{P}<10^{-3}\right)$ to genotype using Taqman assay. Four SNPs ((rs10447475, rs4621668, rs11215400 and rs10926784) were successfully genotyped. The average squared difference between the count of the same allele in the imputed and genotyped version of these 4 SNPs was low ranging from $0.02-0.065$ indicating that the concordance was high (Additional file 1: Figure S2).

\section{"Integrated analyses" of SNP loci, basal expression and drug cytotoxicity}

We also performed integrated analyses of SNPs, expression array and cytotoxicity data $[18,23]$. To do that, we began with SNPs that had P values $<10^{-3}$. We selected a less stringent $\mathrm{P}$ value cutoff to include as many potential candidates as possible for follow-up functional genomic studies. Next, we tested expression probe sets that were associated with these SNPs, followed by association of those expression probe sets with drug IC50 values, ie we performed an "integrated analysis". In these analyses, we used SNP loci, defined as a region that contained at least 2 SNPs with $\mathrm{P}<10^{-4}$ or 1 SNP with $\mathrm{P}<10^{-4}$, plus 3 additional SNPs with $\mathrm{P}<10^{-3}$ within $+/-100 \mathrm{~kb}$ surrounding the most significant SNPs. All of the SNPs within each of those loci are listed in Additional file 1: Table S2, which includes genotyped as well as imputed SNPs. We identified 11 loci containing 166 SNPs for gemcitabine and 23 loci with 187 SNPs for AraC that were associated with IC50 values for these two drugs, respectively (Table 1). Four loci containing 4 genes - HLA-DRA, ZNF215, MASS1, and PLD5 - were common to both drugs (Table 1).

The integrated analyses identified 66 SNPs in 6 loci that were associated with gemcitabine IC50 values and the expression of 12 genes represented by 17 probesets. Those 17 probesets were also associated with gemcitabine
IC50 values $\left(\mathrm{P}<10^{-4}\right)$. The integrated analyses also identified 36 SNPs in 3 loci that were associated with AraC IC50 values and the expression of 9 genes (10 probesets) (Table 2). For gemcitabine, 19 SNPs were within cis-regulatory regions for PIGB or C3orf23. No cis-regulation between SNP and gene expression was identified for AraC. Of interest, SNPs in PIGB were associated with the expression of that gene (lowest $\mathrm{P}=5.97 \times 10^{-9}$ ) as well as the expression of FKBP5 (lowest $\mathrm{P}=2.70 \times 10^{-6}$ ), a gene that we previously reported to play an important role in response to gemcitabine and $\mathrm{AraC}$ as well as many other chemotherapeutic agents including gemcitabine and AraC $[17,27]$. We next moved to further analyses of candidate genes identified during the integrated analysis.

\section{Follow-up functional validation of candidate genes in cancer cells}

Since the regulation of gene expression is tissue specific [28], we wanted to functionally validate in cancer cell lines candidate genes selected based on our analysis performed with LCLs. The tumor cell lines that we selected were based on the expression of the genes of interest and on the clinical uses of these two drugs. Gemcitabine is used in the treatment of pancreatic cancer but it is also used to treat other solid tumors such as breast cancer, while AraC is first-line therapy for acute myelogenous leukemia (AML). Therefore, we selected one human pancreatic cancer cell line, SU86, one breast cancer cell line, MDA-MB-231 and two leukemia cell lines, BDCM and THP1, to functionally characterize the genes of interest. Twenty-six genes were selected based on a series of criteria including association $\mathrm{P}$ value, SNP locus, whether the gene was expressed in LCLs and the biological function of the genes (Table 3 and Figure 2). To determine the functional impact of those genes, we used specific siRNA pools to knockdown the 26 candidate genes, followed by QRT-PCR and MTS cytotoxicity assay. Eleven genes showed an effect on gemcitabine cytotoxicity, 10 on AraC and 5 were common to both drugs. Knockdown of PIGB, ZADH2, PSME3, DOK6, TGFBI, and HLA-DRA in both SU86 and MDA-MB-231 cells significantly desensitized the cells to gemcitabine (Table 3 and Figure 3), consistent with the association study results. Knockdown of C4orf169, TUSC3, LNX2, 


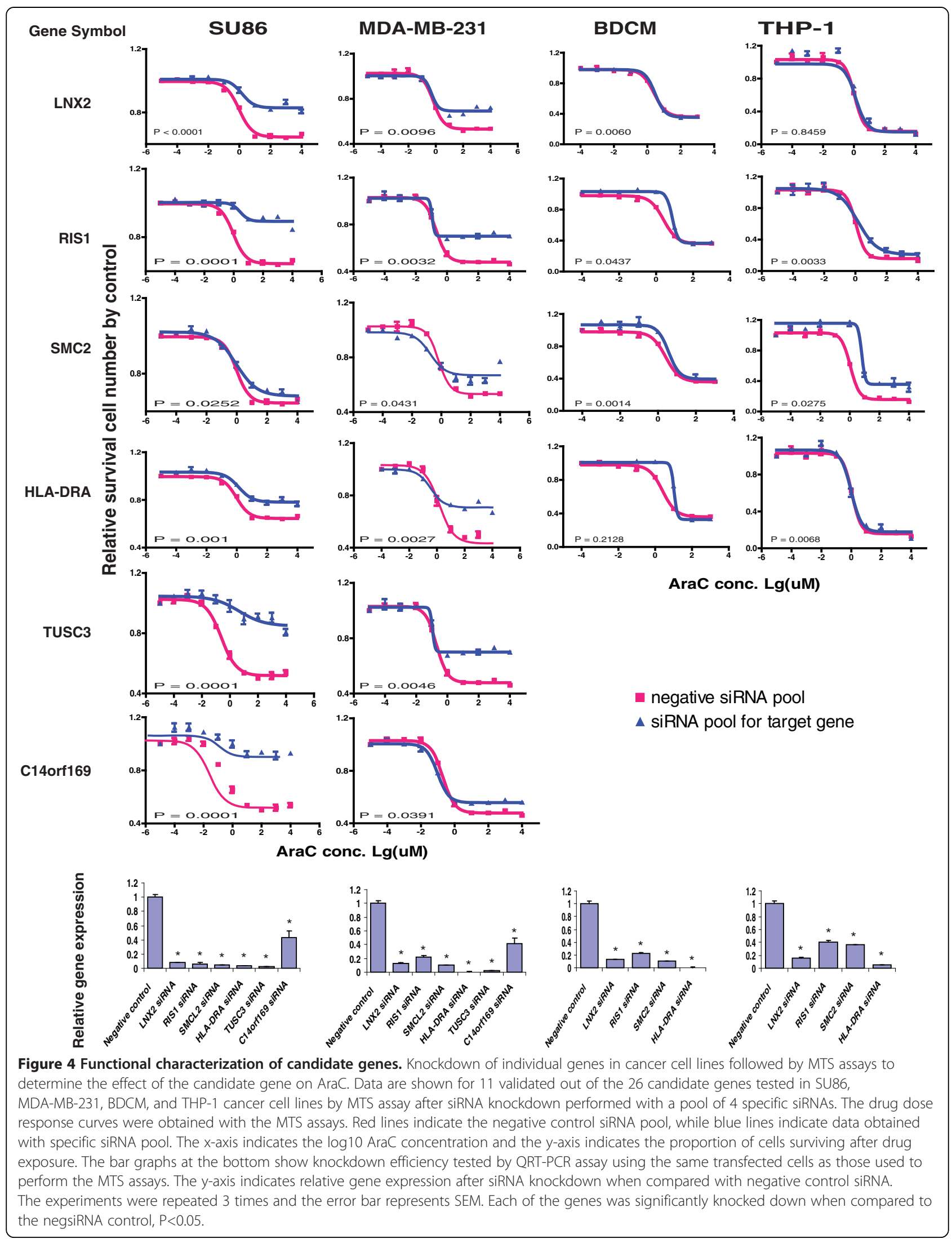




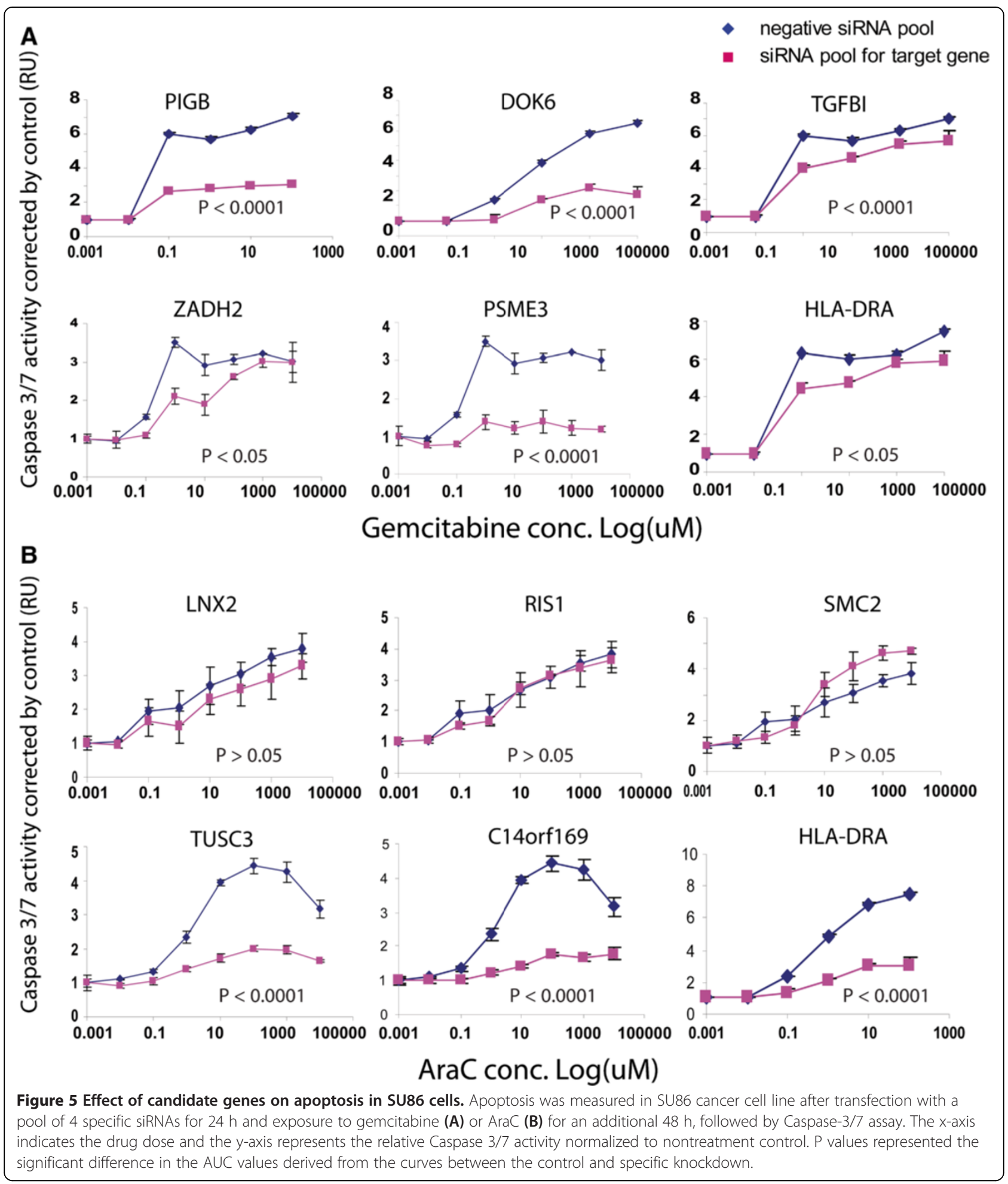

RIS1, and SMC2 and HLA-DRA in both SU86 and MDA-MB-231 cells significantly desensitized the cells to AraC (Table 3 and Figure 4). Finally, knockdown of HLA-DRA in THP-1 leukemia cells, LNX2 in BDCM cells, and SMC2 and RIS1 in both THP1 and BDCM cells also desensitized the cells to $\mathrm{AraC}$, results that were also consistent with our association results (Figure 4). 
Table 4 Functional studies of candidate genes

\begin{tabular}{|c|c|c|c|c|c|c|c|c|c|c|c|}
\hline \multirow{2}{*}{$\begin{array}{l}\text { Gene } \\
\text { symbol }\end{array}$} & \multirow{2}{*}{$\begin{array}{l}\text { Caspase-3/7 } \\
\text { activity }\end{array}$} & \multicolumn{10}{|c|}{ Cancer-related Cignal Reporter Array } \\
\hline & & $\begin{array}{l}\text { Wnt (TCF/ } \\
\text { LEF) }\end{array}$ & $\begin{array}{l}\text { Notch } \\
\text { (RBP-JK) }\end{array}$ & $\begin{array}{l}\text { p53/DNA damage } \\
\text { (p53) }\end{array}$ & $\begin{array}{c}\text { TGF } \beta \text { (SMAD2/ } \\
3 / 4)\end{array}$ & $\begin{array}{c}\text { cell cycle (E2F/ } \\
\text { DP1) }\end{array}$ & $\begin{array}{l}\text { NFKB } \\
\text { (NFKB) }\end{array}$ & $\begin{array}{l}\text { c-Myc (Myc/ } \\
\text { Max) }\end{array}$ & $\begin{array}{l}\text { Hypoxia } \\
\text { (HIF1A) }\end{array}$ & $\begin{array}{l}\text { MAPK /ERK (Elk- } \\
1 / \text { SRF) }\end{array}$ & $\begin{array}{l}\text { MAPK /JNK } \\
\quad(\mathrm{AP}-1)\end{array}$ \\
\hline PIGB & Decrease & No & No & No & No & No & Decrease & Decrease & No & Decrease & Decrease \\
\hline $\mathrm{ZADH} 2$ & Decrease & No & No & No & No & No & No & Increase & No & No & No \\
\hline PSME3 & Decrease & No & Increase & No & Decrease & No & No & Increase & Decrease & No & No \\
\hline DOK6 & Decrease & No & No & No & No & No & Decrease & No & No & No & Decrease \\
\hline TGFBI & Decrease & No & No & Increase & No & No & Decrease & Decrease & Decrease & Decrease & Decrease \\
\hline C140rf169 & Decrease & No & Increase & Increase & No & No & Increase & Increase & No & Increase & Increase \\
\hline TUSC3 & Decrease & No & No & No & Decrease & Decrease & No & No & Decrease & No & No \\
\hline $\begin{array}{l}\text { RIS1 } \\
\text { (TMEM158) }\end{array}$ & No & No & No & No & No & No & No & Increase & No & No & No \\
\hline LNX2 & No & No & No & No & No & No & No & No & No & Increase & No \\
\hline$S M C 2$ & No & No & No & No & No & No & No & No & No & No & No \\
\hline HLA-DRA & Decrease & No & Increase & No & No & No & Increase & No & No & No & No \\
\hline
\end{tabular}

Functional characterization of 11 genes using the Cancer-related Cignal Reporter Array (SABioscience).

Transcription factors for each signal pathway are listed in parenthesis. "Increase" means at least a 2 -fold increase of luciferase activity in cells treated with specific siRNA compared with cells treated with negative control siRNA; while "decrease" indicates at least a 50\% decrease of luciferase activity in control cells. "No" means no alteration in luciferase activity after siRNA knockdown. 


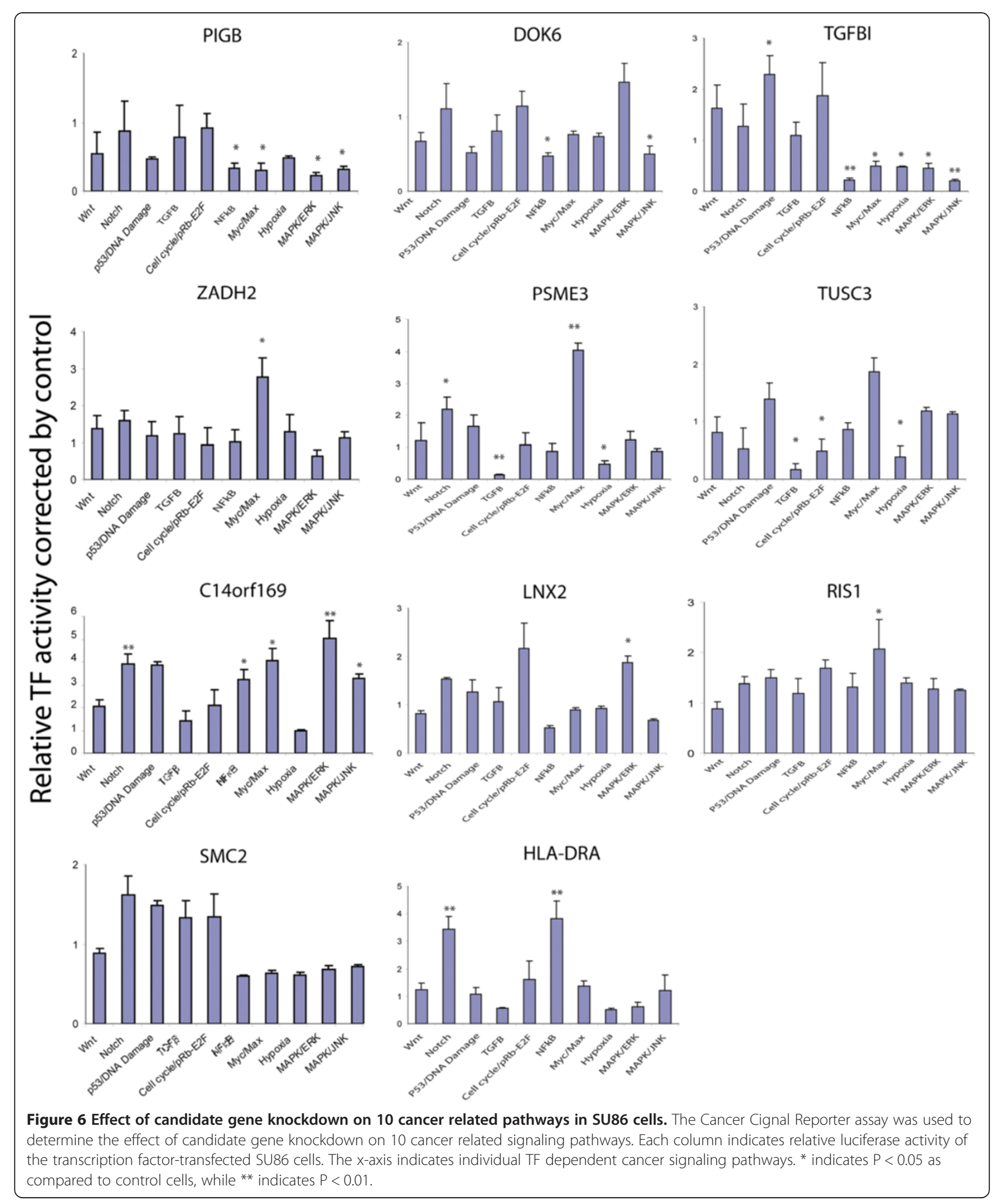


Table 5 The top seven SNPs in PIGB that were associated with gemcitabine cytotoxicity and its expression in LCLs by integrated analysis

\begin{tabular}{|c|c|c|c|c|c|c|c|c|c|c|c|c|c|}
\hline \multicolumn{5}{|c|}{ SNP } & \multicolumn{3}{|c|}{ Gene } & \multicolumn{2}{|c|}{ SNP vs. IC50 } & \multicolumn{2}{|c|}{ SNP vs. Expression } & \multicolumn{2}{|c|}{ Expression vs. IC50 } \\
\hline rsID & Chr & Position & Region & MAF & Probeset & Gene symbol & Chr & $R$ value & $P$ value & $R$ value & $P$ value & $\mathrm{R}$ value & $P$ value \\
\hline 2290344 & 15 & 53407088 & Coding & 0.253 & 205452_at & $P I G B$ & 15 & 0.339 & $1.75 \mathrm{E}-05$ & -0.340 & $1.06 \mathrm{E}-08$ & -0.212 & 5.31E-03 \\
\hline 2290344 & 15 & 53407088 & Coding & 0.253 & 242760_x_at & $P / G B$ & 15 & 0.339 & $1.75 \mathrm{E}-05$ & -0.301 & 4.81E-07 & -0.294 & $8.98 \mathrm{E}-05$ \\
\hline 47774760 & 15 & 53376504 & 5'-upstream & 0.416 & 205452_at & $P I G B$ & 15 & 0.326 & 3.63E-05 & -0.283 & $2.48 \mathrm{E}-06$ & -0.212 & $5.31 \mathrm{E}-03$ \\
\hline$\$ 4774760$ & 15 & 53376504 & 5'-upstream & 0.416 & 242760_x_at & $P I G B$ & 15 & 0.326 & $3.63 \mathrm{E}-05$ & -0.240 & $6.85 \mathrm{E}-05$ & -0.294 & $8.98 \mathrm{E}-05$ \\
\hline 024695 & 15 & 53426597 & Intron & 0.285 & 205452 & $P / G B$ & 15 & 0.321 & $5.00 \mathrm{E}-05$ & -0.326 & 4.60E-08 & -0.212 & $5.31 \mathrm{E}-03$ \\
\hline rs8024695 & 15 & 53426597 & Intron & 0.285 & 242760_x_at & $P I G B$ & 15 & 0.321 & $5.00 \mathrm{E}-05$ & -0.282 & $2.56 \mathrm{E}-06$ & -0.294 & $8.98 \mathrm{E}-05$ \\
\hline s12050587 & 15 & 53414820 & Intron & 0.450 & 205452_at & $P I G B$ & 15 & J. & $1.23 \mathrm{E}-04$ & -0.246 & 4.54E-05 & -0.212 & $5.31 \mathrm{E}-03$ \\
\hline rs28668016 & 15 & 53398725 & $5^{\prime}-U T R$ & 0.365 & 205452_at & $P / G B$ & 15 & 0.304 & $1.31 \mathrm{E}-04$ & -0.346 & 5.97E-09 & -0.212 & 5.31E-03 \\
\hline 28668016 & 15 & 53398725 & $5^{\prime}-U T R$ & 0.365 & 242760_x_at & $P I G B$ & (5) & 0.304 & $1.31 \mathrm{E}-04$ & -0.274 & $5.28 \mathrm{E}-06$ & -0.294 & $8.98 \mathrm{E}-05$ \\
\hline rs11636687 & 15 & 53392444 & 5'-upstream & 0.421 & 205452_at & $P I G B$ & 15 & 0.302 & 1.53E-04 & -0.287 & $2.22 \mathrm{E}-06$ & -0.212 & 5.31E-03 \\
\hline rs7174876 & 15 & 53406853 & Intron & 0.423 & 205452_at & $P I G B$ & 15 & 0.284 & 4.06E-04 & -0.261 & 1.64E-05 & -0.212 & $5.31 \mathrm{E}-03$ \\
\hline
\end{tabular}

$\mathrm{R}$ values represent correlation coefficients for associations. We performed integrated analysis among the SNPs and mRNA expression of the PIGB gene as well as gemcitabine cytotoxicity. The only cis-associated SNPs with PIGB gene expression were listed.

We next wanted to determine whether the cytotoxic effects of those genes might involve apoptosis. Therefore, we performed caspase-3/7 activity assays after knockdown of the candidate genes in SU86 cells. As shown in Figure 5A and 5B, down-regulation of PIGB, DOK6, TGFBI, ZADH2, PSME3, and HLA-DRA in SU86 cells significantly decreased caspase-3/7 activity after treatment with gemcitabine as compared with negative control siRNA-treated cells. Similar results were also observed for $\mathrm{AraC}$ treatment following siRNA knockdown of TUSC3, C14orf169, and HLA-DRA. However, knockdown of LNX2, RIS1, and SMC2 did not alter the cellular caspase-3/7 activity (Table 4 ), suggesting that a different mechanism was involved.

Finally, we used the Cancer Cignal Finder Array (SABioscience) that consists of 10 dual-luciferase reporter gene assays to determine whether our candidate genes might affect any of the 10 cancer-related signaling pathways in SU86 cells by measuring changes in transcriptional activities of 10 key transcription factors (TF) after knockdown of each candidate gene. We observed changes in transcriptional activity of several TFs after knockdown of specific genes in SU86 cells, suggesting that these genes might be involved in the regulation of a particular cancer-related signaling pathway or pathways that might contribute to resistance to gemcitabine and AraC (Figure 6 and Table 3). For example, knockdown of PIGB resulted in a decrease in transcriptional activity of Elk-1/SRF, AP1, NFkB, and Myc/MAX in SU86 cells, indicating a down-regulation of these signaling pathways. Knockdown of DOK6 dramatically decreased the transcription activities of both $\mathrm{NFKB}$ and AP1 in the $\mathrm{NFKB}$ and MAPK/JNK pathways, while the activity of the transcription factor Myc/MAX that is involved in the c-Myc pathway was increased significantly after ZADH2 knockdown. However, we did not observe any significant changes after SMC2 knockdown.

\section{Functional characterization of PIGB SNPs}

When we performed integrated analysis among SNPs, gene expression and gemcitabine cytotoxicity, we found that the only cis-regulated SNPs mapped to PIGB. Knockdown of PIGB resulted in desensitization of cancer cells to gemcitabine. PIGB contained 7 SNPs that were associated both with gemcitabine response $\left(\mathrm{P}<10^{-3}\right)$ and with its own gene expression $\left(\mathrm{P}<10^{-4}\right)$ (Table 5). PIGB expression was also significantly correlated with gemcitabine cytotoxicity $\left(\mathrm{P}=8.95 \times 10^{-5}\right.$ and $\mathrm{P}=5.31 \times 10^{-3}$ for two different probe sets for PIGB mRNA). We also determined LD patterns for those 7 SNPs using HapMap data for each ethnic group. As shown in Figure 7A, LD patterns differed among the three ethnic groups. In both $\mathrm{CHB} / \mathrm{JPT}$ and $\mathrm{CEPH}$ groups, those 7 SNPs were in tight LD, while there was not significant linkage among the SNPs in the YRI population. The top 3 SNPs in PIGB, including rs2290344, a nonsynonymous coding SNP (M161T) in exon 4, rs28668016 in the $5^{\prime}$-UTR, and rs11636687 in the $5^{\prime}$ flanking region (Table 5) were selected for further functional characterization.

We first determined PIGB expression levels in 37 LCLs selected on the basis of genotypes for those 3 SNPs using both QRT-PCR assay and expression array data to confirm the association between the SNPs and PIGB expression. Cells carrying the variant alleles showed significantly lower expression levels than did WT cells (Figure 7B). We next determined the functional impact of these 3 SNPs. As shown in Figure 7C, overexpression of a construct for the PIGB coding SNP 


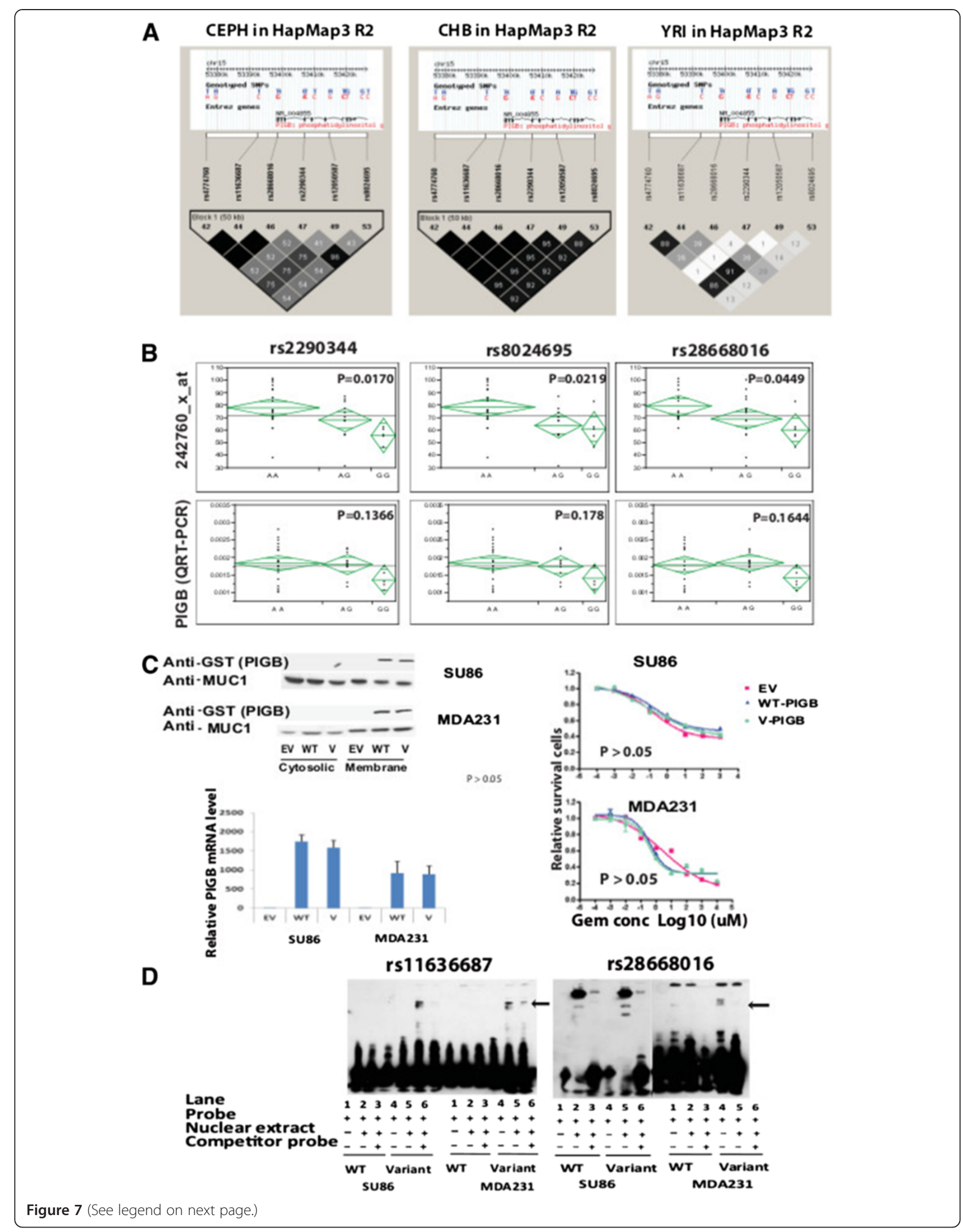


Figure 7 Functional characterization of SNPs in the PIGB gene. (A) Patterns of linkage disequilibrium (LD) within $\sim 200$ Kb surrounding the rs3797418 SNP among three different ethnic groups using HapMap3 R2 data as a reference. The top 7 SNPs in PIGB are arranged in order from $5^{\prime}$ to $3^{\prime}$, as shown in the gene structure above each plot. Black indicates combinations where $R^{2}=1$ and linkage of disequilibrium (LOD) $\geq 2$; light grey, combinations where $0<R^{2}<1$ and LOD $\geq 2$; white, where $R^{2}=0$ and $L O D<2$. (B) Association between SNPs and PIGB expression measured by QRT-PCR assay and microarray using 37 randomly selected LCLs. (C) Effect of the nonsynonymous coding SNP (rs2290344, M161T) on PIGB mRNA expression, protein expression and response to gemcitabine. PIGB mRNA and protein levels were determined in SU86 and MDA-MB-231 cells transfected with either PIGB wild-type or variant constructs with GST-tags. Antibody against GST (Antibody \#2622, Cell Signaling Inc.) was used for detection of PIGB expression, and Antibody against MUC1 (VU4H5 Mouse mAb \#4538, Cell Signaling Inc.) served as a loading control in Western Blot assay. Gemcitabine cytotoxicity performed with the MTS assay was performed in cells transfected with WT and variant constructs. No differences were observed between WT and variant SNP for any of the phenotypes tested. (D) EMSAs were performed for two regulatory SNPs in PIGB gene. The arrows indicate different binding pattern between WT and variant sequences for rs 11636687 and rs286680016.

(rs2290344, M161T) in SU86 and MDA-MB-231 cells did not alter either mRNA or protein levels, nor did it have an effect on gemcitabine cytotoxicity. We then determined whether the two SNPs in regulatory regions, rs11636687 and rs28668016, might have functional impact. We performed electrophoresis mobility shift assays (EMSAs) for these two SNPs to determine whether there might be differences in binding patterns for possible transcription factors. Interestingly, the results from EMSA showed that DNA-protein binding was significantly increased for the probe containing the variant sequences for these two SNPs in both SU86 and MDAMB-231 cells (Figure 7D). These results suggested that these two SNPs might alter the binding of transcription factors and, as a result, affect PIGB expression level.

\section{Discussion}

We previously performed a genome wide SNP association study with $550 \mathrm{~K}$ SNPs obtained with Illumina HumanHap550 BeadChips for the same cell lines to identify common polymorphisms that might influence both gene expression and response to these two drugs [18]. In the present study, we expanded the number of SNPs from $550 \mathrm{~K}$ to include over 1.3 million SNPs and selected candidate genes for functional follow-up studies based on SNP loci. This dense SNP coverage made it possible to identify many more candidates for functional follow-ups. That enabled us to take a different approach by focusing on "SNP loci" instead of single SNPs. The results listed in Table 3 show that 11 of 26 candidate genes selected in this fashion were validated functionally, while only two other genes from the previous $550 \mathrm{k}$ studies were functionally validated [18].

We also tested the concordance of the results generated with $550 \mathrm{~K}$ and 1.3 million SNPs if we had used the same strategy as we did in the current study, i.e. using SNP loci to perform the association studies. The majority of top SNP peaks from the $550 \mathrm{~K}$ SNP data for both drugs displayed less significant SNPs for each locus as compared to the 1.3 million SNP data (Additional file 1: Table S3). These observations illustrate the advantage of the present selection strategy for candidate identification, as well as the advantage of using denser SNP coverage.

Of the 26 candidate genes that we identified for further siRNA screening followed by MTS assay, eleven candidate genes, including PIGB, TGFBI, DOK6, PSME3, ZADH2, TUSC3, C14orf169, SMC2, LNX2, RIS1, and HLA-DRA, showed a significant effect on response to gemcitabine and/or AraC in SU86 and/or MDA-MB231 cells. To identify potential pathways with which these genes might be involved, we used a dual luciferase reporter gene assay to assess the impact of these genes on 10 major cancer-related signaling pathways. As shown in Figure 6 and Table 3, except for the SMC2 gene, knockdown of the other 10 genes in SU86 cells significantly altered activities, based on the luciferase assay for at least one of the 10 cancer related signaling pathways. Genes such as TGFB1 showed changes for the most pathways. While TGFB1 has been well studied, genes such as C14orf169, an unknown gene, also showed increased activity in 7 of the 10 pathways.

We also observed that the activities of the Elk-1/SRF, $\mathrm{AP} 1, \mathrm{NF}_{\mathrm{K}} \mathrm{B}$, and Myc/MAX pathways were significantly decreased in SU86 cells when PIGB was down-regulated by a specific siRNA. PIGB, a gene of the phosphatidylinositol glycan (PIG) class B, encodes an enzyme involved in the synthesis of a glycosylphosphatidylinositol (GPI) anchor that is a membrane attachment structure for many proteins, including membranous enzymes, receptors, differentiation antigens, and other biologically active proteins [29]. GPI anchoring is essential for the expression of many of those proteins in either biological processes or cancer progression [30,31]. The PIGB protein is a GPI mannosyltransferase III and is required for the transfer of the third mannose into the core structure of the GPI anchor [29,32]. Previous studies have demonstrated that other PIG class members, such as PIGU and PIGT, are oncogenes in either human bladder cancer or breast cancer, respectively [33,34]. Our findings indicate that PIGB is involved in sensitizing cancer cells to both gemcitabine and AraC, suggesting a possible role in oncogenic pathways as well as chemoresistance. The 8 PIGB SNPs were also associated with the expression of 
FKBP5, a gene that we previously reported to be important for gemcitabine and $\mathrm{AraC}$ response [17,27]. Furthermore, PIGB expression itself is also correlated with FKBP5 gene expression. Although down regulation of PIGB altered FKBP5 mRNA level, overexpression of FKBP5 in PIGB stable knockdown cell lines did not change response to gemcitabine or AraC (Additional file 1: Figure S3). These observations indicate that PIGB influences the cytotoxicity of the two cytidine analogues through mechanisms that differ from FKBP5, in spite of the correlation of their expression levels observed in the LCLs. The exact mechanisms by which PIGB affects gemcitabine and AraC cytotoxicity need to be explored in the course of future experiments.

In addition to the characterization of candidate genes, we also focused on SNPs in the PIGB gene that showed cis-regulation of PIGB expression. SNPs in regulatory regions can influence drug response through an influence on gene expression. During our analysis, we found that most SNP associations with expression were through trans-regulation. The reason that we focused on SNPs in PIGB is because those SNPs displayed cis-regulations of PIGB and knockdown of PIGB showed an effect on cytotoxicity. The EMSA results also demonstrated "shifts" for the variant SNP sequences (Figure 7D), suggesting that PIGB gene expression might be regulated through binding to those transcription factors.

Previous studies demonstrated that one mechanism by which SNPs might influence drug cytotoxicity is through transcription regulation in either a cis- or trans-manner [18,35-37]. In this analysis, we found SNPs that could both have cis or trans relationship. In addition to the SNPs that cis regulate PIGB, we also found that SNPs close to C3orf 23 were not only cis-associated with its own gene expression, but also trans-correlated with the expression of $Z A D H 2$ which was confirmed to affect drug response of gemcitabine in our functional validation study. How those genetic variations located in the upstream of C3orf23 affect the expression of ZADH2 gene in a trans- manner remains unknown. One mechanism might be that those SNPs nearby C3orf23 could alter DNA sequence binding to transcription factors (TFs), microRNA, or other long non-coding RNA (lnc RNA), thus affect transcriptional regulation of their target genes including $Z A D H 2$ gene, which could in turn, affect gemcitabine response.

\section{Conclusions}

In summary, this study performed with LCLs followed by functional characterization has enhanced our understanding of the action of gemcitabine and $\mathrm{AraC}$ in the therapy of cancer. Although there are limitations associated with the use of LCLs [38,39], this system has proven to be extremely useful, both to generate pharmacogenomic hypothesis and to test pharmacogenomic signals identified during the clinical GWAS [19-21]. Future studies using patient samples will now be required to confirm the candidates identified during this study.

\section{Additional file}

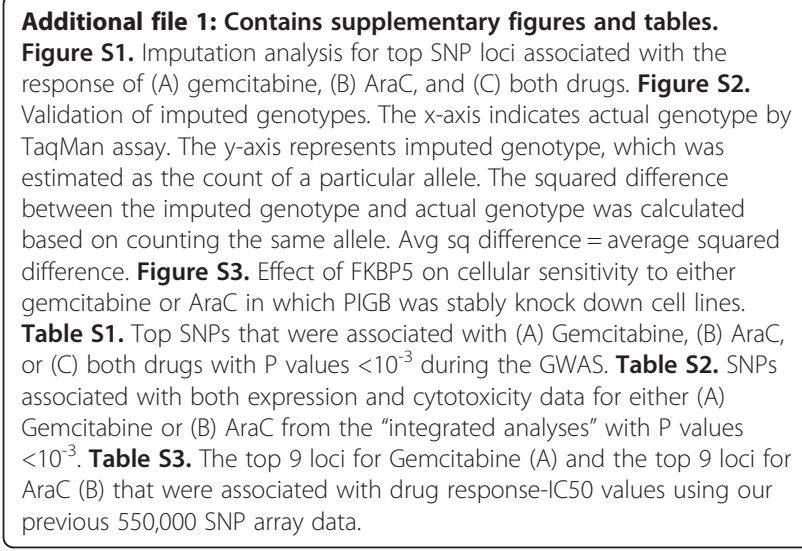

\section{Abbreviations}

AraC: Cytosine arabinoside; LCL: Lymphoblastoid cell line;

RRM1: Ribonucleotide reductase; CDA: Cytidine deaminase; CA:

Caucasian-American; AA: African-American; HCA: African-American;

EMSA: Electrophoresis mobility shift assays; QRT-PCR: Quantitative reverse transcription-PCR; QC: Quality control; HWE: Hardy-Weinberg equilibrium; AML: Acute myelogenous leukemia; TF: Transcription factors;

GWAS: Genome-wide association studies; LD: Linkage disequilibrium.

\section{Competing interests}

The authors declare that they have no competing interests.

\section{Authors' contributions}

$L L, N N$ and $L W$ designed the study and wrote the manuscript. $L L$ and $N N$ performed the experiments. $L L, B F, K K, G J, A B$ and $L W$ analyzed the data. $L L$, NN, BK and LW wrote the manuscript. All authors read and approved the final manuscript.

\section{Acknowledgements}

This study was supported in part by U.S. National Institutes of Health research grants K22 CA130828, R01 CA138461, P50 CA102701, U19 GM61388 (The Pharmacogenomics Research Network), ASPET-Astellas Award, a PhRMA Foundation "Center of Excellence in Clinical Pharmacology" Award, and the Gerstner Family Career Development Awards in Individualized Medicine.

\section{Author details}

${ }^{1}$ Division of Clinical Pharmacology, Department of Molecular Pharmacology and Experimental Therapeutics, Mayo Clinic, Rochester, Minnesota, USA. ${ }^{2}$ Division of Biomedical Statistics and Informatics, Department of Health Sciences Research, Mayo Clinic, Rochester, Minnesota, USA. ${ }^{3}$ Current affiliation: Department of Biostatistics, University of Kansas Medical Center, Kansas City, Kansas, USA.

Received: 7 June 2013 Accepted: 10 January 2014 Published: 1 February 2014

\section{References}

1. Tomasson MH, Xiang Z, Walgren R, Zhao Y, Kasai Y, Miner T, Ries RE, Lubman O, Fremont DH, McLellan MD, Payton JE, Westervelt P, DiPersio JF, Link DC, Walter MJ, Graubert TA, Watson M, Baty J, Heath S, Shannon WD, Nagarajan R, Bloomfield CD, Mardis ER, Wilson RK, Ley TJ: Somatic mutations and germline sequence variants in the expressed tyrosine 
kinase genes of patients with de novo acute myeloid leukemia. Blood 2008, 111:4797-4808.

2. Heinemann V, Xu YZ, Chubb S, Sen A, Hertel LW, Grindey GB, Plunkett W Cellular elimination of 2',2'-difluorodeoxycytidine 5'-triphosphate: a mechanism of self-potentiation. Cancer Res 1992, 52:533-539.

3. Heinemann V, Hertel LW, Grindey GB, Plunkett W: Comparison of the cellular pharmacokinetics and toxicity of 2 ',2'-difluorodeoxycytidine and 1-beta-D-arabinofuranosylcytosine. Cancer Res 1988, 48:4024-4031.

4. Kindler HL: In focus: advanced pancreatic cancer. Clin Adv Hematol Oncol 2005, 3:420-422.

5. Kern W, Estey EH: High-dose cytosine arabinoside in the treatment of acute myeloid leukemia: Review of three randomized trials. Cancer 2006, 107:116-124.

6. Hertel LW, Boder GB, Kroin JS, Rinzel SM, Poore GA, Todd GC, Grindey GB: Evaluation of the antitumor activity of gemcitabine (2',2'-difluoro-2'-deoxycytidine). Cancer Res 1990, 50:4417-4422.

7. Sabeti PC, Varilly P, Fry B, Lohmueller J, Hostetter E, Cotsapas C, Xie X, Byrne EH, McCarroll SA, Gaudet R, Schaffner SF, Lander ES, Frazer KA, Ballinger DG, Cox DR, Hinds DA, Stuve LL, Gibbs RA, Belmont JW, Boudreau A, Hardenbol P, Leal SM, Pasternak S, Wheeler DA, Willis TD, Yu F, Yang H, Zeng C, Gao Y, Hu H, et al: Genome-wide detection and characterization of positive selection in human populations. Nature 2007, 449:913-918.

8. Altshuler D, Daly MJ, Lander ES: Genetic mapping in human disease. Science 2008, 322:881-888.

9. Baum AE, Akula N, Cabanero M, Cardona I, Corona W, Klemens B, Schulze TG Cichon S, Rietschel M, Nothen MM, Georgi A, Schumacher J, Schwarz M, Abou Jamra R, Hofels S, Propping P, Satagopan J, Detera-Wadleigh SD, Hardy J, McMahon FJ: A genome-wide association study implicates diacylglycerol kinase eta (DGKH) and several other genes in the etiology of bipolar disorder. Mol Psychiatry 2008, 13:197-207.

10. Wang L, McLeod HL, Weinshilboum RM: Genomics and drug response. N Engl J Med 2011, 364:1144-1153.

11. Wang L, Weinshilboum RM: Pharmacogenomics: candidate gene identification, functional validation and mechanisms. Hum Mol Genet 2008, 17:R174-R179.

12. Kim SR, Saito Y, Maekawa K, Sugiyama E, Kaniwa N, Ueno H, Okusaka T, Morizane C, Yamamoto N, Ikeda M, Yoshida T, Minami H, Furuse J, Ishii H, Saijo N, Kamatani N, Ozawa S, Sawada J: Thirty novel genetic variations in the SLC29A1 gene encoding human equilibrative nucleoside transporter 1 (hENT1). Drug Metab Pharmacokinet 2006, 21:248-256.

13. Kim SR, Saito Y, Maekawa K, Sugiyama E, Kaniwa N, Ueno H, Okusaka T, Ikeda M, Morizane C, Yamamoto N, Yoshida T, Kamatani N, Furuse J, Ishii H, Saijo N, Ozawa S, Sawada J: Twenty novel genetic variations and haplotype structures of the DCK gene encoding human deoxycytidine kinase (dCK). Drug Metab Pharmacokinet 2008, 23:379-384.

14. Kwon WS, Rha SY, Choi YH, Lee JO, Park KH, Jung JJ, Kim TS, Jeung HC, Chung HC: Ribonucleotide reductase M1 (RRM1) 2464G>A polymorphism shows an association with gemcitabine chemosensitivity in cancer cell lines. Pharmacogenet Genomics 2006, 16:429-438.

15. Sugiyama E, Kaniwa N, Kim SR, Kikura-Hanajiri R, Hasegawa R, Maekawa K, Saito Y, Ozawa S, Sawada J, Kamatani N, Furuse J, Ishii H, Yoshida T, Ueno H, Okusaka T, Saijo N: Pharmacokinetics of gemcitabine in Japanese cancer patients: the impact of a cytidine deaminase polymorphism. J Clin Oncol 2007, 25:32-42.

16. Yonemori $\mathrm{K}$, Ueno H, Okusaka T, Yamamoto $\mathrm{N}$, Ikeda M, Saijo N, Yoshida T, Ishii H, Furuse J, Sugiyama E, Kim SR, Kikura-Hanajiri R, Hasegawa R, Saito Y Ozawa S, Kaniwa N, Sawada J: Severe drug toxicity associated with a single-nucleotide polymorphism of the cytidine deaminase gene in a Japanese cancer patient treated with gemcitabine plus cisplatin. Clin Cancer Res 2005, 11:2620-2624.

17. Li L, Fridley B, Kalari K, Jenkins G, Batzler A, Safgren S, Hildebrandt M, Ames M, Schaid D, Wang L: Gemcitabine and cytosine arabinoside cytotoxicity: association with lymphoblastoid cell expression. Cancer Res 2008, 68:7050-7058

18. Li L, Fridley BL, Kalari K, Jenkins G, Batzler A, Weinshilboum RM, Wang L: Gemcitabine and arabinosylcytosin pharmacogenomics: genome-wide association and drug response biomarkers. PLOS One 2009, 4:e7765.

19. Ingle JN, Schaid DJ, Goss PE, Liu M, Mushiroda T, Chapman JA, Kubo M, Jenkins GD, Batzler A, Shepherd L, Pater J, Wang L, Ellis MJ, Stearns V, Rohrer DC, Goetz MP, Pritchard KI, Flockhart DA, Nakamura Y, Weinshilboum RM: Genome-wide associations and functional genomic studies of musculoskeletal adverse events in women receiving aromatase inhibitors. J Clin Oncol 2010, 28:4674-4682.

20. Liu M, Ingle JN, Fridley BL, Buzdar AU, Robson ME, Kubo M, Wang L, Batzler A, Jenkins GD, Pietrzak TL, Carlson EE, Goetz MP, Northfelt DW, Perez EA, Williard CV Schaid DJ, Nakamura Y, Weinshilboum RM: TSPYL5 SNPs: association with plasma estradiol concentrations and aromatase expression. Mol Endocrinol 2013, 27:657-670

21. Liu M, Wang L, Bongartz T, Hawse JR, Markovic SN, Schaid DJ, Mushiroda T, Kubo M, Nakamura Y, Kamatani N, Goss PE, Ingle JN, Weinshilboum RM: Aromatase inhibitors, estrogens and musculoskeletal pain: estrogendependent T-cell leukemia 1A (TCL1A) gene-mediated regulation of cytokine expression. Breast Cancer Res 2012, 14:R41.

22. Abo R, Hebbring S, Ji Y, Zhu H, Zeng ZB, Batzler A, Jenkins GD, Biernacka J, Snyder K, Drews M, Fiehn O, Fridley B, Schaid D, Kamatani N, Nakamura Y, Kubo M, Mushiroda T, Kaddurah-Daouk R, Mrazek DA, Weinshilboum RM: Merging pharmacometabolomics with pharmacogenomics using '1000 Genomes' single-nucleotide polymorphism imputation: selective serotonin reuptake inhibitor response pharmacogenomics. Pharmacogenet Genomics 2012, 22:247-253.

23. Niu N, Qin Y, Fridley BL, Hou J, Kalari KR, Zhu M, Wu TY, Jenkins GD, Batzler A Wang L: Radiation pharmacogenomics: a genome-wide association approach to identify radiation response biomarkers using human lymphoblastoid cell lines. Genome Res 2010, 20:1482-1492.

24. Browning SR, Browning BL: Rapid and accurate haplotype phasing and missing-data inference for whole-genome association studies by use of localized haplotype clustering. Am J Hum Genet 2007, 81:1084-1097.

25. 1000 Genomes Project Consortium, Abecasis GR, Auton A, Brooks LD, DePristo MA, Durbin RM, Handsaker RE, Kang HM, Marth GT, McVean GA An integrated map of genetic variation from 1,092 human genomes. Nature 2012, 491:56-65.

26. Storey JD, Tibshirani R: Statistical significance for genomewide studies. Proc Natl Acad Sci U S A 2003, 100:9440-9445.

27. Pei H, Li L, Fridley BL, Jenkins GD, Kalari KR, Lingle W, Petersen G, Lou Z, Wang L: FKBP51 affects cancer cell response to chemotherapy by negatively regulating Akt. Cancer Cell 2009, 16:259-266.

28. Dimas AS, Deutsch S, Stranger BE, Montgomery SB, Borel C, Attar-Cohen H, Ingle C, Beazley C, Gutierrez Arcelus M, Sekowska M, Gagnebin M, Nisbett J, Deloukas P, Dermitzakis ET, Antonarakis SE: Common regulatory variation impacts gene expression in a cell type-dependent manner. Science 2009, 325:1246-1250.

29. Takahashi $M$, Inoue N, Ohishi K, Maeda $Y$, Nakamura N, Endo Y, Fujita T, Takeda J, Kinoshita T: PIG-B, a membrane protein of the endoplasmic reticulum with a large lumenal domain, is involved in transferring the third mannose of the GPI anchor. EMBO J 1996, 15:4254-4261.

30. Masterson WJ, Doering TL, Hart GW, Englund PT: A novel pathway for glycan assembly: biosynthesis of the glycosyl-phosphatidylinositol anchor of the trypanosome variant surface glycoprotein. Cell 1989, 56:793-800

31. Doering TL, Masterson WJ, Hart GW, Englund PT: Biosynthesis of glycosyl phosphatidylinositol membrane anchors. J Biol Chem 1990, 265:611-614.

32. Sutterlin C, Escribano MV, Gerold P, Maeda Y, Mazon MJ, Kinoshita T, Schwarz RT, Riezman H: Saccharomyces cerevisiae GPI10, the functional homologue of human PIG-B, is required for glycosylphosphatidylinositol-anchor synthesis. Biochem J 1998, 332(Pt 1):153-159.

33. Guo Z, Linn JF, Wu G, Anzick SL, Eisenberger CF, Halachmi S, Cohen Y, Fomenkov A, Hoque MO, Okami K, Steiner G, Engles JM, Osada M, Moon C, Ratovitski E, Trent JM, Meltzer PS, Westra WH, Kiemeney LA, Schoenberg MP, Sidransky D, Trink B: CDC91L1 (PIG-U) is a newly discovered oncogene in human bladder cancer. Nat Med 2004 10:374-381

34. Wu G, Guo Z, Chatterjee A, Huang X, Rubin E, Wu F, Mambo E, Chang X, Osada M, Sook Kim M, Moon C, Califano JA, Ratovitski EA, Gollin SM, Sukumar S, Sidransky D, Trink B: Overexpression of glycosylphosphatidylinositol (GPI) transamidase subunits phosphatidylinositol glycan class T and/or GPI anchor attachment 1 induces tumorigenesis and contributes to invasion in human breast cancer. Cancer Res 2006, 66:9829-9836.

35. Kim DH, Jung HD, Kim JG, Lee J-J, Yang D-H, Park YH, Do YR, Shin HJ, Kim MK, Hyun MS, Sohn SK: FCGR3A gene polymorphisms may correlate with response to frontline R-CHOP therapy for diffuse large B-cell lymphoma. Blood 2006, 108:2720-2725. 
36. Ryan BM, Robles Al, Harris CC: Genetic variation in microRNA networks: the implications for cancer research. Nat Rev Cancer 2010, 10:389-402.

37. Wapinski O, Chang HY: Long noncoding RNAs and human disease. Trends Cell Biol 2011, 21:354-361.

38. Feng WH, Hong G, Delecluse HJ, Kenney SC: Lytic induction therapy for Epstein-Barr virus-positive B-cell lymphomas. J Virol 2004, 78:1893-1902.

39. Feng WH, Israel B, Raab-Traub N, Busson P, Kenney SC: Chemotherapy induces lytic EBV replication and confers ganciclovir susceptibility to EBV-positive epithelial cell tumors. Cancer Res 2002, 62:1920-1926.

doi:10.1186/1471-2164-15-93

Cite this article as: Li et al.: Discovery of genetic biomarkers

contributing to variation in drug response of cytidine analogues using human lymphoblastoid cell lines. BMC Genomics 2014 15:93.

\section{Submit your next manuscript to BioMed Central} and take full advantage of:

- Convenient online submission

- Thorough peer review

- No space constraints or color figure charges

- Immediate publication on acceptance

- Inclusion in PubMed, CAS, Scopus and Google Scholar

- Research which is freely available for redistribution 